\title{
Impactos da liberalização do comércio de etanol entre Brasil e Estados Unidos sobre o uso da terra e emissão de $\mathrm{CO}_{2}$
}

\author{
Vanessa Nardy \\ Faculdade de Economia, Administraçáo e \\ Contabilidade de Ribeirāo Preto (FEA-RP), \\ Universidade de São Paulo (USP) \\ Angelo Costa Gurgel \\ Escola de Economia de São Paulo (EESP), \\ Fundação Getúlio Vargas (FGV).
}

\section{Palavras-chave}

etanol, tarifas de importação, emissão de gases de efeito estufa, mudanças no uso da terra.

Classificação JEL F18, Q24, Q16.

Keywords

ethanol, import tariffs, greenhouse gases emissions, land use changes.

JEL Classification F18, Q24, Q16.

\section{Resumo}

Investigar os potenciais impactos de uma redução nas tarifas de importação norte-americana ao etanol brasileiro sobre as mudanças no uso da terra e na emissão de gases de efeito estufa provenientes dessas mudanças é o objetivo do presente trabalho. Utiliza-se uma versão do modelo econômico global GTAP capaz de simular como o aumento na produção brasileira de etanol afetaria o uso da terra e a emissão de $\mathrm{CO}_{2}$ tanto no país como no mundo. Os resultados indicam aumento nas áreas de cultura e redução de áreas de pastagem e florestas no país e no mundo, com incrementos modestos em emissão de $\mathrm{CO}_{2}$, compensados pela reduçáo das emissóes no consumo de combustíveis fósseis. Conclui-se que a liberalização comercial não compromete a capacidade do etanol de cana-de-açúcar em contribuir com reduçôes líquidas em emissão de gases de efeito estufa, mesmo que sejam consideradas emissóes de mudanças no uso da terra.

\section{Abstract}

This paper investigates the potential impacts from a cut in the U.S. trade tariffs to the Brazilian ethanol on land use and greenhouse gas emissions from such changes. A version of the GTAP global economic model is used to simulate how an increase in the Brazilian ethanol production could affect land use and $\mathrm{CO}_{2}$ emissions in the country and worldwide. The results indicate an increases in cropland areas and decrease in pastureland and forest areas, with small increments in $\mathrm{CO}_{2}$ emissions, which are offset by lower emissions from reduced consumption of fossil fuels. It can be concluded that the potential of sugarcane ethanol in reducing net greenhouse gas emissions is not affected by the trade liberalization, even when changes in land use are considered. 


\section{1_Introdução}

Atualmente verifica-se intensa preocupação ambiental por parte dos governos e das sociedades em geral. Os efeitos nocivos do aquecimento global e os danos causados pelo homem ao meio ambiente são facilmente percebidos quando analisada a conjuntura mundial atual: alteração drástica no clima, maior ocorrência de catástrofes naturais, alteração em biomas e ecossistemas e diminuição da diversidade animal e vegetal são alguns dos indícios que têm sido relacionados à má preservação do habitat pelo ser humano.

A preocupação com a redução da emissão de gases de efeito estufa, principal causador do aquecimento terrestre, levou à busca por alternativas de geração de energia menos agressivas ao meio ambiente, e de preferência, provenientes de matéria-prima renovável. Com base nessas buscas, os biocombustíveis tomaram destaque no cenário mundial como alternativa potencialmente adequada na substituição dos combustíveis fósseis na matriz energética mundial. Produzidos com base em matérias-primas de origem agrícola, substituem a utilização dos combustíveis derivados do petróleo com grande eficiência e economia nas emissóes.

Diante disso, o crescimento mundial do mercado de biocombustíveis atingiu taxas surpreendentes nos últimos anos, reflexo da utilização de políticas de estímu- lo à produção e à utilização de biocombustíveis no mercado internacional, além da constante busca pela melhoria em termos de eficiência energética. E é nesse cenário que o Brasil despontou como grande produtor e também como o maior exportador de etanol proveniente da cana-de-açúcar do mundo.

Contudo, o mercado mundial de etanol ainda é muito protegido por políticas de comércio internacional que impedem maior fluxo de comércio. O Brasil tem como principal mercado consumidor os Estados Unidos, que subsidiam a sua produção de etanol a partir do milho e impõem tarifas sobre a importação do produto brasileiro. Além disso, dúvidas quanto à verdadeira sustentabilidade da produção em larga escala de combustíveis renováveis provenientes de matéria-prima agrícola têm sido levantadas em debates internacionais, em razão da competição por área para produção de alimentos e fibras, bem como do risco de aumentar a pressão de expansão da fronteira agrícola sobre áreas de vegetação natural. Essas questóes permitem levantar os seguintes questionamentos: quais seriam os efeitos de um aumento no comércio de etanol entre Brasil e EUA sobre a expansáo da fronteira agrícola no país e o desmatamento? Como essa expansão afetaria a emissão de gases de efeito estufa e o balanço de emissão desse biocombustível? 
Considerando essas questóes, o objetivo do presente trabalho é analisar quais seriam os possíveis impactos para a produção brasileira de etanol, em termos de mudanças no uso da terra e em emissão de gases de efeito estufa, caso haja a extinção de políticas protecionistas norte-americanas sobre os biocombustíveis. A motivação para tal análise surgiu da renovação recente por parte do Congresso americano do acordo que estabelece as tarifas e os subsídios sobre o etanol, no fim de 2010, que frustrou as expectativas de produtores brasileiros e consumidores norte-americanos de redução naquela proteção, bem como das discussões sobre a sustentabilidade desse biocombustível. Com isso, pretende-se estimar se prejuízos ao meio ambiente, em termos de emissão de gases, poderiam ser proporcionados pela liberalização desse comércio.

Espera-se dessa forma contribuir para a literatura pertinente pela análise empírica inédita no Brasil da competição entre biocombustíveis e outros usos agrícolas pelo uso do recurso terra diante da intensificação do comércio internacional. A próxima seção apresenta uma discussão sobre a importância e a evolução dos biocombustíveis e a contextualização do comércio de etanol entre Brasil e EUA. A terceira seção apresenta a metodologia utilizada para a análise empírica. A quarta seção mostra e discute os resultados obtidos, enquanto a seção final apresenta as conclusóes.

\section{2_Biocombustíveis, etanol e mudanças no uso da terra}

Entende-se por biocombustível todo composto energético produzido a partir de matéria-prima de origem biológica e de caráter renovável, em contraste com os combustíveis convencionais que têm como base materiais fósseis e de origem finita. Esse conceito apareceu pela primeira vez no início do século XX, com Rudolf Diesel e Henry Ford, na Exposição Internacional de Paris, quando foram apresentados os primeiros motores movidos a óleo de amendoim e etanol.

Embora seja uma tecnologia conhecida desde o começo do século passado, a substituição dos combustíveis de origem fóssil só se mostrou viável com o aumento expressivo do preço do petróleo nos denominados "Choques do Petróleo", ocorridos ao longo do século XX. A grande oscilação nos preços do principal combustível da sociedade contemporânea fez com que países como os Estados Unidos e grande parte da Europa entrassem em recessão e desencadeassem grande desequilíbrio na economia global. Na tentativa de evitar novas alterações drásticas no suprimento interno de energia e buscando maior au- 
tonomia na produção e no uso de combustíveis, os países perceberam nos biocombustíveis uma interessante alternativa para modificar a sua matriz energética e reduzir a importância dos países da OPEP.

Outro forte argumento a favor dos biocombustíveis passou a ser amplamente discutido desde a década de 1980, quando se iniciaram as principais discussóes acerca da preocupação com as mudanças climáticas no globo causadas pelo chamado "efeito estufa". Um dos principais gases de efeito estufa é o dióxido de carbono $\left(\mathrm{CO}_{2}\right)$, liberado principalmente na reação de combustáo em motores que envolvem um combustível de origem fóssil. A busca de fontes alternativas de energia, bem como a substituição do uso de combustíveis fósseis, tornou-se o principal objetivo dos países na corrida pela redução de emissão de gases. É nesse cenário de busca pela independência energética e de preocupação com a redução da emissão de GEEs que os biocombustíveis ganharam destaque entre os países.

A produção e o uso mundial dos biocombustíveis apresentaram grande crescimento nos últimos anos. Segundo Pires e Schechtman (2009), a produção mundial de etanol aumentou 18,6\% entre 2000 e 2008, enquanto a de biodiesel cresceu cerca de 37,3\% no mesmo período.

Os Estados Unidos destacam-se como maior produtor e consumidor de eta- nol. ${ }^{1} \mathrm{O}$ etanol norte-americano é produzido a partir do milho e utilizado como aditivo na gasolina. Contudo, em razão da imensa magnitude do mercado de combustíveis norte-americano, em 2009, esse consumo representou apenas $0,3 \%$ do total de combustível consumido em veículos automotivos, segundo a U.S. Energy Information Administration (EIA, 2010).

Os norte-americanos são um exemplo "da aplicação combinada de padróes regulatórios e incentivos financeiros na promoção dos biocombustíveis" (Pires; Schechtman, 2009). O acordo Energy Policy Act, assinado em 2005, institui em uma de suas sessões o programa denominado Renewable Fuel Standard (RFS, 2010a), que estabelece um cronograma para a adição de combustíveis renováveis à gasolina, objetivando atingir o consumo de 7,5 bilhões de galóes de etanol em 2012. Para assegurar a implementação do RFS, os norte-americanos contam com a Environmental Protection Agency (EPA), que regulamenta os níveis de adição do biocombustível à gasolina de acordo com a demanda por combustíveis no país. Em dezembro de 2007, o RFS ganhou nova versão formulada pelo Energy Independence and Security Act (EISA) (Congress of the United States of America, 2007). Entre as principais mudanças, está o aumento do volume obrigatório de combustível renovável misturado
${ }^{1} \mathrm{O}$ consumo nos EUA atingiu 11,1 bilhôes de galóes em 2009, de acordo com o American Petroleum Institute (2010). 
à gasolina e a expansão do período do programa. Agora se estima um consumo de 36 bilhōes de galóes para 2022. Além disso, o RFS2 estabelece que uma parcela desses combustíveis renováveis seja suprida pelos chamados "biocombustíveis avançados", provenientes da celulose e da biomassa. Esse grupo de biocombustíveis deve apresentar porcentagens mínimas de redução de emissão de gases de efeito estufa durante todo o seu ciclo produtivo, quando comparado aos combustíveis fósseis. Após a intervenção da União da Indústria da Cana-de-Açúcar (UNICA, 2009), sugerindo uma readequação da metodologia e das consideraçóes usadas ao avaliar o etanol proveniente da cana-de-açúcar, o biocombustível brasileiro foi reconhecido como avançado, em fevereiro de 2010. Nesse sentido, a produção de etanol de milho norte-americana não atenderia à demanda estipulada no RFS2. O biocombustível da cana, porém, é fortemente tributado ao entrar em solo norte-americano, o que dificulta a expansão desse comércio. Assim, a aceitação da EPA é um argumento que pode ser usado a favor para facilitar a eliminação das tarifas estipuladas sobre o produto brasileiro.

O etanol norte-americano é produzido a partir do milho. Contudo, a rentabilidade industrial da produção do biocombustível a partir do grão é muito inferior à encontrada no etanol de cana-de-açúcar: para cada hectare de cana cultivada, são extraídos 7 mil litros de etanol, ao passo que essa relação para o milho é de apenas 3 mil litros por hectare cultivado.

Além da baixa produtividade industrial, o etanol norte-americano encontra na segurança alimentar grande obstáculo para sua consolidação. $\mathrm{O}$ milho é o principal componente da ração no confinamento de aves, bovinos e suínos, além de ter grande representatividade na alimentação diária da população. Com o aumento da demanda de milho para a produçáo do biocombustível, o setor de alimentos viu-se pressionado pela elevaçáo dos preços dessa commodity, aumentando o custo dos alimentos para a população.

Assim, o uso do etanol nos Estados Unidos também é visto como uma alternativa para a melhoria ambiental e a redução da dependência energética; no entanto, é obstruído pela localização, pelos altos custos de produção, pelo baixo rendimento e pela competiçáo com os alimentos. $\mathrm{O}$ biocombustível americano "requer generosos subsídios para competir como substituto da gasolina e mesmo assim não tem competitividade nos estados da costa leste dos Estados Unidos" (Scandiffio, 2005).

Embora exista grande potencial para o comércio de etanol entre Brasil e Estados Unidos, esse mercado é fortemente afetado pela prática de políticas comer- 
ciais que visam proteger o mercado norte-americano, seus produtores e consumidores. A legislação americana considera um subsídio de 45 centavos de dólar por galão de etanol aos produtores, chamado de Volumetric Ethanol Excise Tax Credit (VEETC), e a tarifa de importação ao etanol estrangeiro, de 54 centavos de dólar por galão, renovada em dezembro de 2010.

As duas principais formas de intervenção do governo norte-americano na demanda por etanol é por meio de mandatos como o Renewable Fuel Standard (RFS, 2010b) e fazendo uso de políticas comerciais como tarifas e subsídios. Como dito anteriormente, o RFS estabelece qual deveria ser a demanda com base nas recomendações de consumo. Por exemplo, em 2011 a demanda norte-americana deveria ser de 12,6 bilhóes de galóes, montante que deve aumentar para 14,4 bilhões de galóes em 2014.

Enquanto isso, os instrumentos de política comercial podem intervir na oferta ou na demanda de acordo com a alocação dos preços. Os subsídios aos produtores têm o poder de aumentar o valor de mercado marginal do etanol pelo montante igual ao crédito concedido. Esse aumento no valor pode estimular a oferta e elevar a produção acima do nível requerido pelo mandato. Outra forma de afetar os mercados é por meio das tarifas de im- portação. Os importadores de etanol devem pagar uma tarifa fixa de 54 centavos de dólar por galáo mais uma ad valorem de 2,5\%. O efeito dessa tarifa é deslocar a oferta de exportação brasileira no mesmo montante que a tarifa de importação. Isso significa que o Brasil não exporta etanol para os Estados Unidos a menos que os preços americanos sejam suficientes para cobrir os custos de transporte e as tarifas de importação.

$\mathrm{O}$ efeito líquido da combinação dessas duas políticas (os subsídios aos produtores e as tarifas de importação) é a redução dos incentivos à importação do etanol proveniente do Brasil, quando comparado com um cenário onde há ausência desses instrumentos de política comercial.

A crescente preocupação ambiental ligada ao aquecimento global tem feito com que a emissão de gases de efeito estufa ganhe destaque nos debates sobre a sustentabilidade da agricultura e dos biocombustíveis no longo prazo. Isso porque a emissão, associada ao ciclo produtivo das culturas que envolvem o preparo do solo, o plantio, a manutenção da cultura e a colheita, é de grande representatividade no cálculo do balanço final de emissão dos produtos que têm em sua composição matérias-primas de origem agrícola. O fenômeno de mudança no uso da terra ocorre quando a produção agropecuá- 
ria ocupa uma nova área antes destinada a outra finalidade. Essa pode ocorrer de maneira direta, quando uma cultura se encontra em uma porção de terra que apresentava outro uso no período anterior ou, de maneira indireta, onde uma cultura é realocada por outra, e aquela cultura substituída diretamente avança para novas áreas de expansão. Assim, essa discussão sobre as mudanças do uso da terra (Land Use Changes - LUC) tornou-se elemento central na análise da verdadeira sustentabilidade da produção de biocombustíveis, juntamente com a problemática da disponibilidade de recursos naturais.

Metodologicamente, é muito difícil chegar a uma conclusão sobre a forma mais correta na identificação e na avaliação dos determinantes causais dessas emissóes. A forma que vem sendo mais comumente utilizada na mensuração das causas e dos efeitos é com o uso de "modelos econômicos de projeção agropecuária associados a padróes históricos de substituição de terra obtidos com imagens de satélite" (Nassar, 2009). Para essa finalidade, podem ser usados tanto os modelos de equilíbrio geral como aqueles que representam mercados individualizados, conhecidos como de equilíbrio parcial.

Os modelos econômicos apresentam a alocação de terras para uso das culturas com base no equilíbrio entre a oferta e a demanda de todos os produtos analisados. Em seguida, projeta-se um cenário de choque, como, por exemplo, aumento na demanda de certo produto, e verifica-se a alocação de terras nos dois cenários - a variaçáo entre eles é o chamado "efeito da mudança do uso da terra", que posteriormente será convertido no montante de emissão de gases de efeito estufa associada às mudanças no uso da terra.

Esse tipo de análise é aplicado no caso de choques de demanda causados por alteração no comércio internacional (tarifas, quotas e subsídios) ou adversidades climáticas envolvendo a produção. No presente trabalho, será feita a simulação de um choque que abrange a redução das tarifas sobre a exportação brasileira de etanol para os Estados Unidos. A análise se faz necessária, uma vez que o argumento das emissóes relacionadas ao desmatamento na Amazônia causado pela expansão indireta da cultura da cana-de-açúcar é um ponto relevante nas discussões pela liberalização do comércio. Para isso, será utilizado o referencial teórico de análise do comércio bilateral entre países, além de ferramentas de estimativa de emissão de $\mathrm{CO}_{2}$.

\section{3_Metodologia}

Este estudo visa analisar possíveis impactos ambientais causados pela eliminação 
das tarifas norte-americanas sobre o etanol brasileiro. Para isso, utilizar-se-á um modelo computável de equilíbrio geral para simular o que aconteceria com as mudanças no uso da terra e com a emissão de $\mathrm{CO}_{2}$, caso a política comercial de elevadas barreiras ao etanol brasileiro pelos EUA fosse mantida, ou não.

Segundo Shoven e Walley (1998), modelos de equilíbrio geral representam interação entre múltiplos agentes, que busca a otimização individual e interage através dos mercados de bens e fatores de produção. Na construção dos modelos de equilíbrio geral, são estabelecidas funções de produção para cada setor da economia e funções de utilidade para os consumidores, incorporando elementos micros e macroeconômicos que relacionam os fatores produtivos e os insumos necessários para gerar os produtos de uma economia - notadamente bens e serviços - por meio de um sistema walrasiano de equilíbrio competitivo. Esses modelos são elaborados para reproduzir o equilíbrio inicial de uma economia com base nos seus dados de matrizes de insumo-produto e contabilidade social e, por meio de choques, obter os impactos de mudanças em variáveis exógenas, como impostos, subsídios e tarifas, por exemplo.

O modelo utilizado neste estudo baseia-se no programa de equilíbrio ge- ral GTAP - Global Trade Analysis Project (997) - desenvolvido em 1992 pelo Departamento de Economia Agrícola da Universidade de Purdue, nos Estados Unidos. O projeto é composto de vários elementos, entre eles um modelo computável de equilíbrio geral padrão, um banco de dados e um software para a elaboração do modelo e tratamento dos dados. A evolução do projeto GTAP, ao longo do tempo, tem gerado diversos modelos e avanços no estudo aplicado com o ferramental do equilíbrio geral computável. Esses modelos têm sido extensamente utilizados em pesquisas empíricas de mensuração de mudanças em políticas comerciais para diversos países. De particular importância para a presente pesquisa são os avanços na base de dados e modelagem do GTAP, em termos de representação dos fluxos de energia, do uso da terra, de biocombustíveis e de emissão de gases de efeito estufa.

Esta versão do modelo GTAP foi desenvolvida com base na versão 6.2 (Dimaranan, 2006), com a inclusão de biocombustíveis e seus subprodutos como documentado em Taheripour et al. (2007) e Birur et al. (2008), que ficou conhecida como GTAP-BIO. A base de dados inclui informações sobre produção, consumo e comércio de biocombustíveis originados de grãos, cana-de-açúcar e de sementes 
${ }^{2} \mathrm{O}$ estudo do CARB (2009) utilizou o modelo GTAP para estimar a intensidade de emissão por causa de mudanças no uso da terra, medida em termos de gramas de $\mathrm{CO}_{2}$ por megajoule, para diferentes tipos de biocombustível. A versão do modelo GTAP utilizada pelo CARB e empregada no presente estudo está disponível em: http://www.arb.ca.gov/ fuels/lcfs/lcfs-background. htm\#modeling. Para utilizar o modelo GTAP, é necessário possuir a licença para a base de dados da versão 6 . oleaginosas. Outra sofisticação do modelo utilizado é a consideração de subprodutos da produção de diferentes biocombustíveis, possibilitada pelo trabalho de Taheripour et al. (2008). Este modelo, por sua vez, foi originado da versão do GTAP que incorpora detalhes sobre os mercados domésticos e internacionais de energia e instrumentos de política de mitigação de mudanças climáticas, o GTAP-E, desenvolvido por Burniaux e Truong (2002) e modificado por McDougall e Golub (2009). Birur et al. (2008) incluem os biocombustíveis e suas possibilidades de substituir produtos do petróleo, bem como consideram elasticidades de demanda de energia baseadas nos exercícios de validação histórica de Beckman e Hertel (2009).

A introdução da base de dados de uso da terra no modelo GTAP, considerando zonas agroecológicas em cada região e país, e que permitiu a representação explícita de mudanças no seu uso, foi conduzida por Lee et al. (2009) e possibilitada pelos dados publicamente disponíveis nos trabalhos de Ramankutty et al. (2008) e Monfreda et al. (2008).

O GTAP é um modelo multirregional e multissetorial, que representa as economias em competição perfeita e retornos de escala constantes, com uma descrição completa do valor da produção setorial, de insumos e fatores pelos setores, consu- mo privado e das famílias, fluxos comerciais bilaterais, impostos e subsídios domésticos, tarifas e subsídios às exportações.

Para a realização deste estudo, será utilizada a mesma versão aplicada no estudo do California Air Resource Board (CARB, 2009), ${ }^{2}$ que considera todos os avanços listados anteriormente. Essa versão agrega os 87 países e regióes e os 57 setores de produção originais da base de dados do GTAP em 18 regióes e 21 setores, incluindo os de produção de biocombustíveis (Quadro 1).

\section{1_Estrutura e funcionamento do modelo}

A estrutura do modelo GTAP segue os padrôes comuns de modelos de equilíbrio geral estáticos, do estilo Arrow-Debreu, e pode ser representada pela Figura 1, a seguir. A renda regional de cada país é originada a partir do pagamento do setor produtivo pelo uso dos fatores de produção (terra, capital, trabalho e recursos naturais), que na figura é representada pelo fluxo VOA. Essa renda pode ser alocada entre o consumo das famílias (fluxo PRIVEXP), o consumo do governo (fluxo GOVEXP) e a poupança (fluxo SAVE), através de uma função Cobb-Douglas, e não é possível que os agentes gastem mais do que sua receita. Tudo o que é poupado vai para um banco mundial, e de lá é realocado para as diversas regióes, de acordo com 
Quadro 1_Países e regiões, setores e commodities representados na agregação do GTAP

\begin{tabular}{|c|c|}
\hline Países e regiões & Setores e commodities \\
\hline 1. Estados Unidos & 1. Milho e grãos \\
\hline 2. Canadá & 2. Outros grãos \\
\hline 3. União Europeia (27) & 3. Outras culturas \\
\hline 4. Brasil & 4. Sementes oleaginosas \\
\hline 5. Japão & 5. Cana-de-açúcar \\
\hline 6. China & 6. Outros produtos agrícolas \\
\hline 7. Índia & 7. Pecuária \\
\hline 8. América Latina (exportadores de energia) & 8. Silvicultura \\
\hline 9. Resto da América Latina e Caribe & 9. Produtos animais processados \\
\hline 10. Ex-U.R.S.S. e Leste Europeu (exportadores de energia) & 10. Outros alimentos \\
\hline 11. Resto da Europa & 11. Carvão \\
\hline 12. Oriente Médio e Norte da África (exportadores de energia) & 12. Petróleo \\
\hline 13. África Subsaariana (exportadores de energia) & 13. Gás \\
\hline 14. Resto da África & 14. Outros setores primários \\
\hline 15. Sul da Ásia (exportadores de energia) & 15. Refino do petróleo \\
\hline 16. Resto da Ásia (renda elevada) & 16. Etanol de milho \\
\hline 17. Resto do Sudeste e Sul da Ásia & 17. Etanol de cana-de-açúcar \\
\hline \multirow[t]{4}{*}{ 18. Oceania } & 18. Biodiesel \\
\hline & 19. Indústria intensiva em energia \\
\hline & 20. Eletricidade \\
\hline & 21. Outras indústrias e serviços \\
\hline
\end{tabular}

Fonte: elaboraçấo própria

a demanda por investimentos nos setores produtivos.

Essa forma de distribuição de renda entre os agentes permite que sejam avaliadas variações na renda regional, as quais são utilizadas também como medidas do bem-estar da sociedade como um todo, uma vez que alteraçóes nas políticas analisadas levarão a diferentes alocaçóes de renda entre os agentes.

Pela ótica dos produtores, a renda é gerada pela venda de produtos para con- 
Figura 1_Fluxo de renda GTAP para economias abertas com multirregião

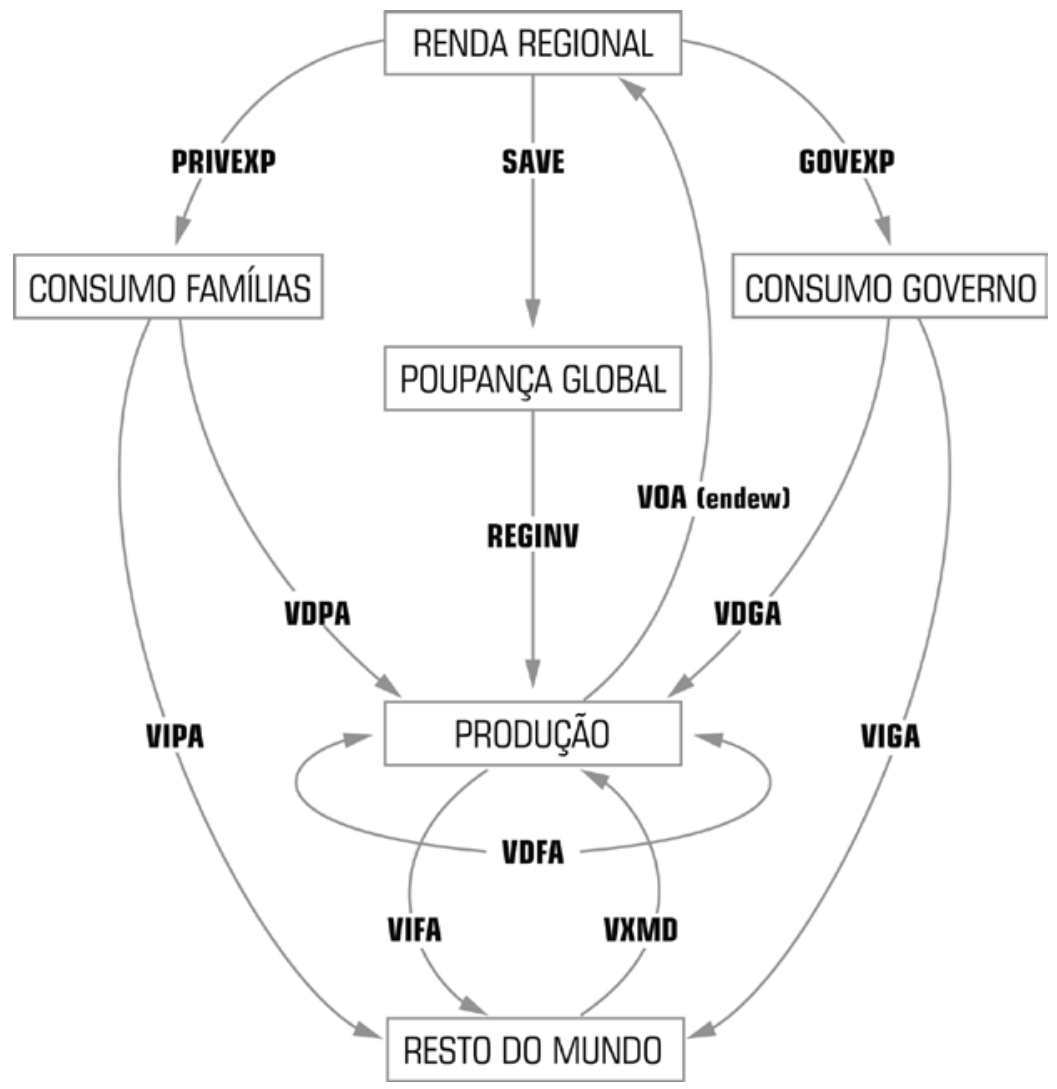

Fonte: Hertel (1997).

${ }^{3}$ Com exceção do nível mais elevado da função de consumo dos agentes privados, que segue uma formulação de elasticidade de diferença constante (Constantdifference of elasticity). go dos fatores, todos os recursos devem ser gastos no consumo e nas importaçóes de bens, bem como na remuneração dos fatores de produção.

A renda das famílias é obtida sob a forma de salários advindos do setor produtivo e deve ser gasta com consumo doméstico e/ou importaçóes de bens (fluxo VIPA). O mesmo acontece com o governo (fluxo VIGA), cuja renda é obtida por meio da tributação.

Tanto o uso de insumos e recursos pelas empresas quanto o consumo de bens e serviços pelas famílias e pelo governo seguem formulações de funçóes aninhadas de produção de elasticidade de substituição constante. ${ }^{3}$ Essas funçóes combinam seus componentes em diferentes níveis seguindo uma hierarquia lógica, como, por exemplo, permitindo a substituição direta, porém limitada, de diferentes fontes de energia; contudo, a substituição indireta é bem mais restrita, ou mesmo uma relaçáo complementar, entre a cesta de insumos energéticos e outros bens ou insumos. A Figura 2 exemplifica a estrutura geral de substituição nas funções de produção. A descrição completa das árvores tecnológica e de consumo, bem como da elasticidade utilizada e suas fontes, é apresentada por Burniaux e Truong (2002).

A Figura 2 ainda representa a possibilidade de substituiçấo entre os insumos 


\section{Figura 2_Árvore tecnológica - estrutura de produção no modelo GTAP4}

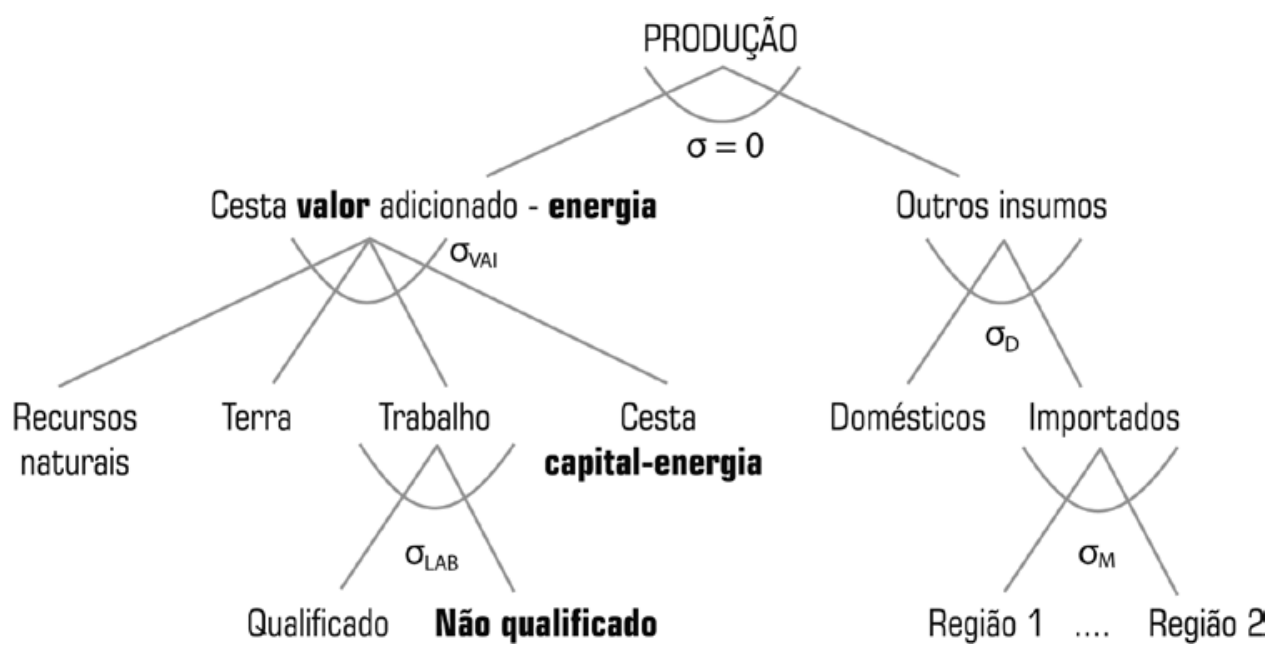

Fonte: Burniaux e Truong (2002)

de origem doméstica e os importados, considerados como substitutos imperfeitos, seguindo a pressuposição de Armington. Ainda, a substituição de um mesmo tipo de bem, vindo de parceiros comerciais diferentes, também é considerada imperfeita.

O comportamento dos agentes econômicos segue os pressupostos comuns da teoria microeconômica, ou seja, os consumidores desejam maximizar sua utilidade sujeita à sua restrição orçamentária enquanto os produtores desejam minimizar seus custos, levando-se em conta o preço dos fatores produtivos e suas restriçóes tecnológicas. O fluxo de transferências de renda na troca de bens, insumos e fatores primários entre os agentes leva a um equilíbrio em preços e quantidades nos diversos mercados.

\section{2_Uso da terra no GTAP}

Mais recentemente, o modelo GTAP tem sido adaptado e utilizado para mensurar as possíveis mudanças no uso da terra, como apresentado em Lee et al. (2009). Algumas aplicaçóes dessa adaptação a questóes relacionadas com biocombustíveis incluem Keeney e Hertel (2009); Hertel et al. (2010) e Tyner et al. (2010). Essa adaptação do modelo permite mensurar os

\footnotetext{
${ }^{4}$ A estrutura apresentada omite, por restriçóes de espaço, a representação das possibilidades de substituição entre capital e insumos energéticos. As letras gregas $\sigma$ representam as elasticidades de substituição em cada nível da árvore tecnológica, sendo específicas de cada setor produtivo. Burniaux e Truong (2002) apresentam em detalhes a estrutura do cesta capital-energia e as diferentes elasticidades de substituição utilizadas no modelo.
} 
efeitos de um choque sobre o uso do solo por áreas de pastagens, culturas e florestas, bem como sobre as áreas destinadas a diferentes grupos de culturas agrícolas. Ainda, o modelo mensura a emissão de $\mathrm{CO}_{2}$ associada às mudanças no uso da terra, como, por exemplo, as emissóes advindas do desmatamento e da substituição de florestas por pastagens e culturas agrícolas.

A transformação do uso da terra no modelo GTAP considera funçóes de elasticidade de transformação constante, que transformam a terra total disponível para agricultura em cada zona agroecológica (ZAE) em três categorias diferentes de uso, quais sejam: culturas, pastagens e florestas. Áreas de culturas são utilizadas apenas para produçáo vegetal, ao passo que pastagens são usadas para pecuária e florestas para silvicultura, produção e extração de madeira. Mudanças no retorno relativo dessas categorias de uso acabam por provocar alteração na quantidade física de cada uma das categorias, preservando-se a área total de terra disponível constante em cada ZAE. A elasticidade de transformação considerada foi baseada nos trabalhos de Lubowski etal. (2006) e Ahmed etal. (2008) e estimada com base nas resposta da oferta de área agrícola diante de mudanças na rentabilidade dessas.

Um aspecto importante da representação de mudanças no uso da terra pe- lo modelo GTAP diz respeito ao uso de um parâmetro que expressa a produtividade de novas áreas convertidas de pastagens ou florestas para áreas de culturas, essencial para preservar a área física total de terra em cada ZAE. Pela falta de informação sobre esse parâmetro, o mesmo foi considerado como equivalente à metade da produtividade observada em áreas agrícolas já existentes, em todas as ZAEs e regióes do mundo. Contudo, em se tratando de países e regióes com vasta extensão territorial e diferentes composiçóes edafoclimáticas que afetam as culturas, é questionável o uso de um único parâmetro que sintetize a razão da produtividade de áreas novas e áreas tradicionais para a produção agrícola. Ainda, no caso do Brasil, se tem observado que as áreas de fronteira agrícola são capazes de reproduzir a produtividade de áreas tradicionais, como tem sido notado em relação à expansão da soja no país, primeiro sobre as áreas de cerrado do Centro-Oeste e mais atualmente sobre as áreas de cerrado e florestas no Norte e no Nordeste do país. Bruce e Carriquiry (2010) testaram a hipótese de que a produtividade de novas áreas agrícolas no Brasil difere de áreas tradicionais no que concerne à cultura da soja e não foram capazes de confirmar tal hipótese.

Dessa forma, procurou-se encontrar na literatura valores mais realistas sobre a ra- 
zão de produtividade de novas áreas agrícolas e áreas tradicionais. $\mathrm{O}$ estudo de Tyner et al. (2010) fez uso de um modelo global de ecossistemas terrestres, capaz de representar os processos químicos e físicos de ciclagem de nutrientes, para estabelecer a razão de produtividade de novas áreas agrícolas e áreas tradicionais para cada ZAE do modelo GTAP. ${ }^{5}$ Os resultados desse estudo apontam para valores de razão de produtividade, em geral, bem superiores ao valor original de 0,5 do modelo GTAP utilizado no estudo CARB (2009). ${ }^{6}$ Isso significa que, diante de uma expansão da produção agrícola ou de biocombustíveis, a necessidade de converter áreas de florestas e pastagens em área de culturas é bem menor no trabalho de Tyner $e t$ al. (2010) do que do CARB (2009), o que deve gerar menos emissão de $\mathrm{CO}_{2}$ advinda de mudanças no uso da terra. No presente estudo, adota-se tanto a razão de produtividade original do GTAP utilizada no estudo CARB (2009) quanto as do estudo de Tyner et al. (2010), comparando-se os resultados sob as duas hipóteses.

\section{4_Resultados e discussões}

Para simular uma redução nas barreiras comerciais norte-americanas ao etanol brasileiro no modelo GTAP, basearam-se nas estimativas feitas pelo estudo de Babcock, Barr e Carriquiry (2010) acerca dos custos e benefícios trazidos para a sociedade de possíveis mudanças nas políticas norte-americanas de importação de etanol. Segundo esses autores, com a manutenção da tarifa sobre o etanol importado do Brasil, projeta-se um comércio de etanol da ordem de 270 milhóes de galóes para 2014, ao passo que, se essa tarifa fosse extinta, o comércio aumentaria para cerca de 1.530 milhóes de galóes. Esses dois níveis de incremento na produção de etanol foram simulados no modelo como choques. A diferença entre os resultados dos dois choques deve permi-

\section{${ }^{5} \mathrm{O}$ estudo de Tyner $e t$}

al. (2010) considera que a produtividade de novas áreas agrícolas difere entre zonas agroecológicas do mundo. Tal produtividade foi estimada valendo-se de um modelo de ecossistemas terrestres global, que simula os

\section{ciclos químicos de nutrientes} nos vegetais e solos, com base em informaçóes sobre clima, solo, relevo e cobertura vegetal. Dessa forma, esse modelo é capaz de captar que, em regióes de maior exuberância vegetal natural, existe maior probabilidade de elevada produtividade agrícola, enquanto, em regióes de clima adverso e vegetação escassa, a produtividade agrícola deve ser baixa. Trata-se, portanto, de uma metodologia cientificamente mais avançada para se inferir sobre a produtividade de novas áreas do que simplesmente supor que essas possuam a metade da produtividade de áreas agrícolas tradicionais.

${ }^{6}$ Os valores dos parâmetros estimados por Tyner et al. (2010) encontram-se no Anexo. 
tir captar os efeitos que a remoção da tarifa norte-americana ao etanol exportado pelo Brasil teria sobre o uso da terra e emissão de gases de efeito estufa no país e no mundo como um todo.

Ainda, foram consideradas duas situaçóes sobre o parâmetro de razão de produtividade de novas áreas sobre áreas tradicionais. Na primeira, utilizam-se os parâmetros originais do modelo GTAP, de que a produtividade de uma nova área de culturas, convertida a partir de pastagens ou florestas naturais, é 50\% menor que a observada nas áreas tradicionais de produção de culturas. Na segunda situação, são usados os parâmetros de produtividade sugeridos por Tyner et al. (2010), que são diferenciados por zona agroecológica. Foram analisados os resultados sobre as variáveis cobertura vegetal, área cultivada e emissão de $\mathrm{CO}_{2}$.

\section{1_Resultados utilizando-se os parâmetros originais do GTAP}

Os resultados encontrados para as variaçóes na cobertura vegetal e uso do solo no Brasil decorrentes do aumento nas exportaçóes de etanol para os EUA indicam aumento na área de culturas entre $110 \mathrm{mil}$ ha até 2014 , caso as tarifas de importação sejam preservadas, e $710 \mathrm{mil} \mathrm{ha}$, se as tarifas forem eliminadas. Isso significa aumento de cerca de $600 \mathrm{mil}$ ha decorren- tes da expansão do comércio por meio da queda nas tarifas. Esse aumento está associado a um incremento de $1.260 \mathrm{mi}$ lhões de galóes na produção de etanol de cana-de-açúcar.

A expansão da área agrícola cultivada ocorre em detrimento da diminuição das áreas de pastagens e florestas, que perdem $400 \mathrm{mil}$ ha e $200 \mathrm{mil}$ ha, respectivamente, como consequência da eliminação das tarifas ao etanol. Esse resultado indica contínua pressão sobre a conversão de outros usos do solo em novas áreas de culturas decorrentes da expansão da produção de cana-de-açúcar para etanol. Contudo, percebe-se que a conversão de áreas de pastagens absorve a maior parte da demanda por novas áreas de culturas, e que o efeito sobre a área de floresta inicial é muito pequeno, da ordem de $0,12 \%$. Vale ressaltar que o choque aqui simulado significa aumento de cerca $21 \%$ na produção e de $123 \%$ nas exportaçóes brasileiras de etanol em relação à safra 2008/2009, quando se considera a eliminação das tarifas americanas ao etanol brasileiro.

Um aspecto importante dos resultados é que o modelo capta em conjunto as mudanças diretas e indiretas de uso do solo. Ou seja, a conversão de áreas de pastagens e de florestas para áreas de culturas pode ocorrer tanto pela necessidade de novas áreas para cana-de-açúcar quanto pela ne- 
Tahela 1_Mudanças na cohertura e uso do solo no Brasil (em milhóes de hectares)

\begin{tabular}{|c|c|c|c|c|c|c|}
\hline & $\begin{array}{l}\text { Cobertura } \\
\text { inicial }\end{array}$ & $\begin{array}{l}\text { Cobertura após c } \\
\ldots \ldots \ldots \ldots \\
\text { c/ tarifa }\end{array}$ & $\begin{array}{l}\text { hoque } \\
\ldots \ldots \ldots \ldots \\
\text { s/tarifa }\end{array}$ & $\begin{array}{l}\text { Variação absolut } \\
\ldots \ldots \ldots \ldots \ldots \\
\text { c/ tarifa }\end{array}$ & $\begin{array}{l}\text { na cobertura } \\
\text { s/ tarifa }\end{array}$ & $\begin{array}{l}\text { Diferença na Variação } \\
\text { c/ e s/ tarifa }\end{array}$ \\
\hline Culturas & 51.68 & 51.79 & 52.39 & 0.11 & 0.71 & 0.60 \\
\hline Pastagens & 180.79 & 180.72 & 180.32 & -0.07 & -0.47 & -0.40 \\
\hline Florestas & 157.52 & 157.48 & 157.28 & -0.04 & -0.24 & -0.20 \\
\hline Outras áreas & 162.44 & 162.44 & 162.44 & 0.00 & 0.00 & 0.00 \\
\hline Total & 552.42 & 552.42. & 552.42. & 0.00 . & 0.00 . & 0.00 \\
\hline
\end{tabular}

Fonte: Resultados do estudo.

cessidade de novas áreas para outras culturas agrícolas que tiveram suas áreas substituídas pela cana-de-açúcar. A Tabela 2 apresenta as alteraçóes nas áreas de culturas agrícolas nos dois cenários. $\mathrm{O}$ aumento da produção de etanol para a comercialização com os EUA requer expansão na área cultivada com cana-de-açúcar sobre as áreas das demais culturas. Ocorre maior deslocamento sobre a área cultivada com culturas oleaginosas, que perdem $110 \mathrm{mil} \mathrm{ha}$ (1\%), e com outros grãos, principalmente arroz e trigo, que perdem $70 \mathrm{mil} \mathrm{ha} \mathrm{(2,7 \% ).}$ Esse resultado parece estar de acordo com o cenário presenciado atualmente no Brasil, em que boa parte da expansão da cultura da cana-de-açúcar vem ocorrendo nos Estados do Centro-Oeste, tradicionais na produção de grãos e oleaginosas. A área total de culturas no Brasil expande em 600 mil (1,45\%) ha para acomodar cerca de $21 \%$ de aumento na área de cana-de-açúcar, ou 870 mil ha a mais.

Os resultados encontrados e comentados acima para o caso do Brasil seguem o mesmo padrão das mudanças mundiais (Tabela 3), de aumento nas áreas de culturas agrícolas e diminuição nas áreas de pastagens e florestas. Contudo, como esse aumento na área de culturas agrícolas no mundo (860 mil ha) foi superior ao montante encontrado para o Brasil (600 mil ha), bem como a queda nas áreas de pastagens e florestas no Brasil foi inferior às quedas mundiais, observa-se desdobramento dos impactos para outros países, via mercados internacionais de produtos agropecuários. Esse resultado é reflexo da queda na produção de algumas culturas agrícolas no Brasil, o que aumenta seus preços nos mercados mundiais, que, por sua vez, respondem com acréscimo na produção dessas. 
Tabela 2_Mudanças nas áreas de culturas no Brasil (em milhões de hectares)

\begin{tabular}{|c|c|c|c|c|c|c|c|}
\hline & Área inicial & $\begin{array}{l}\text { Área após ch } \\
\text { c/ tarifa }\end{array}$ & $\begin{array}{l}\text { que } \\
\text { s/ tarifa }\end{array}$ & $\begin{array}{l}\text { Variação absc } \\
\text { c/ tarifa }\end{array}$ & $\begin{array}{l}\text { luta na área } \\
\text { s/ tarifa }\end{array}$ & $\begin{array}{l}\text { Diferença var } \\
\text { Absoluta }\end{array}$ & $\begin{array}{l}\text { ação c/ e s/ tarifa } \\
\text { \% } \ldots\end{array}$ \\
\hline Milho e cereais ${ }^{1}$ & 12.25 & 12.24 & 12.18 & -0.01 & -0.07 & -0.05 & -0.55 \\
\hline Oleaginosas & 14.39 & 14.36 & 14.25 & -0.03 & -0.14 & -0.11 & -0.97 \\
\hline Cana-de-açúcar & 5.02 & 5.20 & 6.06 & 0.18 & 1.04 & 0.87 & 20.75 \\
\hline Outros grãos $^{2}$ & 3.35 & 3.34 & 3.26 & -0.02 & -0.09 & -0.07 & -2.66 \\
\hline Outras culturas & 13.83 & 13.82 & 13.79 & -0.01 & -0.04 & -0.03 & -0.27 \\
\hline Total & 48.84 & 48.95 & 49.55 & 0.11 & 0.71 & 0.60 . & 1.45 \\
\hline
\end{tabular}

1 Aveia, cevada, centeio e sorgo

2 Arroz e trigo

Fonte: Resultados do estudo.

Tabela 3_Mudanças na cobertura e uso do solo no mundo (em milhões de hectares)

\begin{tabular}{|c|c|c|c|c|c|c|}
\hline & $\begin{array}{l}\text { Cobertura } \\
\text { inicial }\end{array}$ & $\begin{array}{l}\text { Cobertura após } \\
\text { c/ tarifa }\end{array}$ & $\begin{array}{l}\text { hoque } \\
\text { s/tarifa }\end{array}$ & $\begin{array}{l}\text { Variação absolut } \\
\text { c/ tarifa }\end{array}$ & $\begin{array}{l}\text { na cobertura } \\
\text { s/ tarifa }\end{array}$ & $\begin{array}{l}\text { Diferença na variação } \\
\text { c/ e s/ tarifa }\end{array}$ \\
\hline Culturas & 1532.75 & 1532.91 & 1533.77 & 0.16 & 1.01 & 0.86 \\
\hline Pastagens & 2838.31 & 2838.21 & 2837.64 & -0.10 & -0.67 & -0.57 \\
\hline Florestas & 2235.05 & 2234.99 & 2234.70 & -0.05 & -0.34 & -0.29 \\
\hline Outras áreas & 2290.11 & 2290.11 & 2290.11 & 0.00 & 0.00 & 0.00 \\
\hline Total . & 8896.22 & 8896.22 . & 8896.22 . & 0.00 . & 0.00 . & 0.00 \\
\hline
\end{tabular}

Fonte: Resultados do estudo.

A Tabela 4 permite compreender melhor tais mudanças na produção das diferentes culturas em nível mundial. Os resultados sugerem aumento mais pronunciado na área mundial de cana-de-açúcar (4\%), acompanhado de aumentos bem modestos na área de sementes oleaginosas e de queda nas áreas de milho e cereais e outros grãos. Comparando os resultados da Tabela 4 com os da Tabela 2, percebe-se que a variação absoluta da área de cana-de-açúcar no mundo é ligeiramente inferior à observada no Brasil, enquanto a área de oleaginosas cai no Brasil e aumenta 
no mundo. Esse resultado revela que a expansão da cana-de-açúcar promovida pela queda das tarifas norte-americanas ao etanol se dá somente no Brasil, ao passo que, no resto do mundo, ocorre aumento na área de oleaginosas, sendo a soja o principal componente desse segmento agrícola, para compensar a queda na área e na produção brasileira desses produtos. Tal resultado é consequência da mudança no preço relativo mundial dos diferentes produtos agrícolas diante do choque simulado, indicando que as sementes oleaginosas passam a receber maiores preços após as mudanças em ofertas e demandas de culturas em âmbito mundial.

Aqui as emissōes mantiveram-se semelhantes aos resultados encontrados para o Brasil, demonstrando certa homogeneidade nas emissões decorrentes das mudan- ças no uso da terra em todo o mundo. Isso significa que as mudanças na agricultura brasileira provenientes do choque de aumento na produção de etanol provocam impactos em emissóes de mudanças no uso da terra não apenas neste país, mas também nos demais países que se ajustam principalmente pelo aumento da produção das culturas que cedem espaço para a cana-de-açúcar no Brasil, evidenciando que o fenômeno de mudanças no uso da terra é mundial em razão da ligação existente entre os mercados via comércio mundial.

\section{2_Resultados utilizando-se os parâmetros de produtividade de novas áreas obtidos por Tyner et al. (2010)}

Considerando a discussão apresentada na metodologia sobre a incerteza no parâmetro utilizado para representar a produtivi-

Tabela 4_Mudanças nas áreas de culturas no mundo (em milhões de hectares)

\begin{tabular}{|c|c|c|c|c|c|c|c|}
\hline & Área inicial & $\begin{array}{l}\text { Área após cho } \\
\text { c/ tarifa }\end{array}$ & s/ tarifa & $\begin{array}{l}\text { Variação abso } \\
\text { c/ tarifa }\end{array}$ & $\begin{array}{l}\text { uta na área } \\
\text { s/ tarifa }\end{array}$ & $\begin{array}{l}\text { Diferença var } \\
\text { c/ e s/ tarifa } \\
\text { Absoluta }\end{array}$ & \\
\hline Milho e cereais & 294.90 & 294.89 & 294.83 & -0.01 & -0.07 & -0.06 & -0.02 \\
\hline Oleaginosas & 182.39 & 182.40 & 182.53 & 0.02 & 0.14 & 0.12 & 0.07 \\
\hline Cana-de-açúcar & 25.81 & 25.98 & 26.85 & 0.18 & 1.04 & 0.86 & 4.03 \\
\hline Outros grãos & 178.94 & 178.92 & 178.84 & -0.02 & -0.09 & -0.08 & -0.05 \\
\hline Outras culturas & 598.55 & 598.54 & 598.55 & 0.00 & 0.00 & 0.00 & 0.00 \\
\hline Total & 1280.58 & 1280.74 & 1281.59 & 0.16 & 1.01 & 0.86 & 0.08 \\
\hline
\end{tabular}

Fonte: Resultados do estudo. 
dade de uma área recém-transformada de pastagens ou florestas para culturas, um conjunto alternativo de cenários foi simulado, dessa vez utilizando os diferentes parâmetros de produtividade propostos por Tyner et al. (2010). A Tabela 5 apresenta os resultados dessas simulaçóes sobre as mudanças na cobertura e uso do solo no Brasil. Os resultados indicam aumento na área de culturas no Brasil de 60 mil ha pelo incremento nas exportaçóes brasileiras sem redução das tarifas norte-americanas, e 390 mil ha caso as tarifas sejam removidas. Isso significa que a redução da barreira comercial ao etanol estaria associada a um acréscimo de 330 mil ha na área de culturas agrícolas no país. Esse aumento se dá pela redução mais pronunciada nas áreas de pastagens, da ordem de $260 \mathrm{mil} \mathrm{ha,} \mathrm{e}$ de uma redução nas áreas de florestas de cerca de 70 mil ha.
Tais resultados seguem a mesma direção dos observados na Tabela 1, em que se considerou o parâmetro original de produtividade de áreas novas do modelo GTAP. Contudo, as mudanças são bem menos expressivas sob os parâmetros estimados por Tyner et al. (2010), uma vez que tais parâmetros consideram que a redução na produtividade de novas áreas não é tão expressiva quanto a queda de $50 \%$ de produtividade na versão original do modelo GTAP.

Dessa forma, a expansão das áreas de culturas cai de 600 mil hectares para 330 mil hectares. Isso significa que, diante de uma expansão da área de cana-de-açúcar para produção de etanol, se necessita de menor conversão de áreas de pastagem ou de florestas para a produção de culturas, já que cada novo hectare convertido possui produtividade ligeiramente inferior em relação às áreas tradicionalmente utilizadas

Tabela 5_Mudanças na cobertura e uso do solo no Brasil com os parâmetros de Tyner et al. (2010) (em milhóes de hectares)

\begin{tabular}{|c|c|c|c|c|c|c|}
\hline & $\begin{array}{l}\text { Cobertura } \\
\text { inicial }\end{array}$ & $\begin{array}{l}\text { Cobertura após c } \\
\text { c/ tarifa }\end{array}$ & $\begin{array}{l}\text { hoque } \\
\text { s/ tarifa }\end{array}$ & $\begin{array}{l}\text { Variação absoluta } \\
\text { c/ tarifa }\end{array}$ & $\begin{array}{l}\text { na cobertura } \\
\text { s/ tarifa }\end{array}$ & $\begin{array}{l}\text { Diferença na } \\
\text { variação c/ e s/ } \\
\text { tarifa }\end{array}$ \\
\hline Culturas & 51.68 & 51.74 & 52.07 & 0.06 & 0.39 & 0.33 \\
\hline Pastagens & 180.79 & 180.74 & 180.48 & -0.05 & -0.31 & -0.26 \\
\hline Florestas & 157.52 & 157.50 & 157.43 & -0.01 & -0.08 & -0.07 \\
\hline Outras áreas & 162.44 & 162.44 & 162.44 & 0.00 & 0.00 & 0.00 \\
\hline Total. & 552.42. & 552.42. & 552.42. & 0.00 & 0.00 . & 0.00 . \\
\hline
\end{tabular}

Fonte: Resultados do estudo. 
para cultivos. Como os parâmetros estimados por Tyner et al. (2010) foram obtidos através de um modelo de simulação global das dinâmicas dos diferentes ecossistemas terrestres, enquanto o valor do parâmetro original utilizado no GTAP foi gerado por suposição, acredita-se que os resultados gerados com os parâmetros de Tyner et al. são mais apropriados à realidade brasileira e mundial. Outra diferença nos resultados da Tabela 5 em relação aos da Tabela 1 diz respeito à maior proporção de redução nas áreas de pastagens quando do uso do parâmetro estimado por Tyner et al. (2010), de cerca de $78 \%$, enquanto que, com o uso do parâmetro original do GTAP, a redução nas áreas de pastagens corresponde a $66 \% \mathrm{da}$ redução total de áreas de pastagens e florestas juntas.
As mudanças na cobertura e uso do solo estão relacionadas à redistribuição da área de culturas agrícolas. A Tabela 6, a seguir, apresenta as mudanças nas áreas de culturas no Brasil. Os resultados indicam que a redução na barreira comercial norte-americana às exportaçóes de etanol brasileiro estaria associada a um aumento de 19\% na área de cana-de-açúcar e redução entre $1 \%$ e $3 \%$ das demais culturas. Em relação aos cenários simulados anteriormente com o parâmetro original de produtividade de novas áreas do GTAP, os resultados do presente cenário mostram que a expansão da área de cana é ligeiramente menor e gera redução mais pronunciada nas áreas das demais culturas. Isso acontece uma vez que, com a maior produtividade de áreas novas nos parâmetros de Tyner et al. (2010), é possível acomodar a

Tahela 6_Mudanças nas áreas de culturas no Brasil com os parâmetros de Tyner et al. (2010) (em milhões de hectares)

\begin{tabular}{|c|c|c|c|c|c|c|c|}
\hline & Área inicial & $\begin{array}{l}\text { Área após cho } \\
\text { c/ tarifa }\end{array}$ & $\begin{array}{l}\text { que } \\
\text { s/ tarifa }\end{array}$ & $\begin{array}{l}\text { Variação abso } \\
\text { c/ tarifa }\end{array}$ & $\begin{array}{l}\text { uta na área } \\
\text { s/ tarifa }\end{array}$ & $\begin{array}{l}\text { Diferença variaç } \\
\text { c/ e s/ tarifa } \\
\ldots \ldots \ldots \\
\text { Absoluta }\end{array}$ & \\
\hline Milho e cereais & 12.25 & 12.22 & 12.12 & -0.02 & -0.13 & -0.11 & -1.09 \\
\hline Oleaginosas & 14.39 & 14.35 & 14.17 & -0.04 & -0.22 & -0.18 & -1.54 \\
\hline Cana-de-açúcar & 5.02 & 5.19 & 6.00 & 0.17 & 0.98 & 0.81 & 19.51 \\
\hline Outros grãos & 3.35 & 3.33 & 3.24 & -0.02 & -0.12 & -0.10 & -3.46 \\
\hline Outras culturas & 13.83 & 13.81 & 13.71 & -0.02 & -0.12 & -0.09 & -0.85 \\
\hline Total & 48.84 & 48.90 & 49.23. & 0.06 & 0.39 . & 0.33 . & 0.80 \\
\hline
\end{tabular}

Fonte: Resultados do estudo. 
mesma expansão da produção de cana-de-açúcar mediante menor expansão da área total de culturas, visto que cada novo hectare convertido para culturas é mais produtivo que na simulaçáo com o parâmetro original do GTAP.

No que diz respeito a mudanças na cobertura e uso do solo mundialmente, a Tabela 7 evidencia que a retirada da tarifa dos EUA ao etanol brasileiro gera expansão mundial de $480 \mathrm{mil}$ ha nas áreas de culturas, provenientes da contração de $380 \mathrm{mil}$ ha de pastagens e de $100 \mathrm{mil}$ ha de florestas. Como a expansão da área de culturas no Brasil foi de 330 mil ha, a mudança na política comercial bilateral entre EUA e Brasil produz efeitos sobre o uso da terra no resto do mundo, na forma de um incremento de $100 \mathrm{mil}$ ha convertidos para a produção de culturas agrícolas. Esse efeito decorre das interaçôes entre os países nos mercados mundiais de commodities agrícolas. Como o aumento da produção de cana-de-açúcar para etanol no Brasil compete com outras áreas de cultivo agrícola, aquelas culturas que experimentam redução em produção no Brasil acabam sofrendo aumento de preços nos mercados mundiais, o que estimula a produção dessas em terceiros países, pressionando a conversão de áreas de pastagens e florestas para a produçáo de culturas.

Vale notar que as mudanças na cobertura e uso do solo da Tabela 7 são menos pronunciadas do que as estimadas inicialmente apresentadas na Tabela 3, bem como indicam conversão relativamente maior de pastagens do que de florestas. Esse resultado confirma o exposto anteriormente, de que o uso dos parâmetros estimados por Tyner et al. (2010) geram menores impactos sobre áreas de florestas

Tabela 7_Mudanças na cohertura e uso do solo no mundo com os parâmetros de Tyner et al. (2010) (em milhóes de hectares)

\begin{tabular}{|c|c|c|c|c|c|c|}
\hline & $\begin{array}{l}\text { Cobertura } \\
\text { inicial }\end{array}$ & $\begin{array}{l}\text { Cobertura após } \\
\text { c/ tarifa }\end{array}$ & $\begin{array}{l}\text { hoque } \\
\text { s/tarifa }\end{array}$ & $\begin{array}{l}\text { Variaçãa absolut } \\
\text { c/ tarifa }\end{array}$ & $\begin{array}{l}\text { na cobertura } \\
\text { s/ tarifa }\end{array}$ & $\begin{array}{l}\text { Diferença na variação c/ } \\
\text { e s/ tarifa }\end{array}$ \\
\hline Culturas & 1532.75 & 1532.84 & 1533.33 & 0.09 & 0.57 & 0.48 \\
\hline Pastagens & 2838.31 & 2838.24 & 2837.86 & -0.07 & -0.45 & -0.38 \\
\hline Florestas & 2235.05 & 2235.03 & 2234.93 & -0.02 & -0.12 & -0.10 \\
\hline Outras áreas & 2290.11 & 2290.11 & 2290.11 & 0.00 & 0.00 & 0.00 \\
\hline Total. & 8896.22 & 8896.22 & 8896.22 & 0.00 . & 0.00 . & 0.00 . \\
\hline
\end{tabular}

Fonte: Resultados do estudo. 
e pastagens do que o parâmetro original do GTAP, em que a produtividade de uma nova área tem apenas metade da produtividade da área de cultura tradicional, em qualquer região do mundo.

As mudanças nas áreas das diferentes culturas no mundo são apresentadas na Tabela 8 e indicam o aumento na área de cana-de-açúcar e de sementes oleaginosas em detrimento da redução nas áreas das demais culturas. $\mathrm{O}$ aumento absoluto na área mundial de cana-de-açúcar é o mesmo observado no Brasil, o que significa que, no resto do mundo, não ocorrem mudanças na área dessa cultura. Já as quedas nas áreas de milho e cereais, outros grãos e outras culturas são ligeiramente mais pronunciadas, em termos absolutos, no mundo como um todo do que no
Brasil, ao passo que o aumento na área de oleaginosas no mundo é contrário ao observado no Brasil, isto é, de queda na área dessas culturas. Esses resultados indicam que o aumento na produção de cana-de-açúcar no Brasil reduz a área e a produção de soja e oleaginosas no país de forma mais intensa do que de outras culturas, o que provoca mudança relativa no preço internacional em favor dessas commodities.

Esse aumento de preço relativo leva à expansão da área de soja mundialmente em detrimento da área de outras culturas. Em relação aos resultados da Tabela 4 , sobre as mudanças mundiais nas áreas de culturas utilizando o parâmetro de produtividade de áreas novas do GTAP, agora os aumentos em áreas de cana-de-açúcar e oleaginosas no mundo são me-

Tabela 8_Mudanças nas áreas de culturas no mundo com os parâmetros de Tyner et al. (2010) (em milhões de hectares)

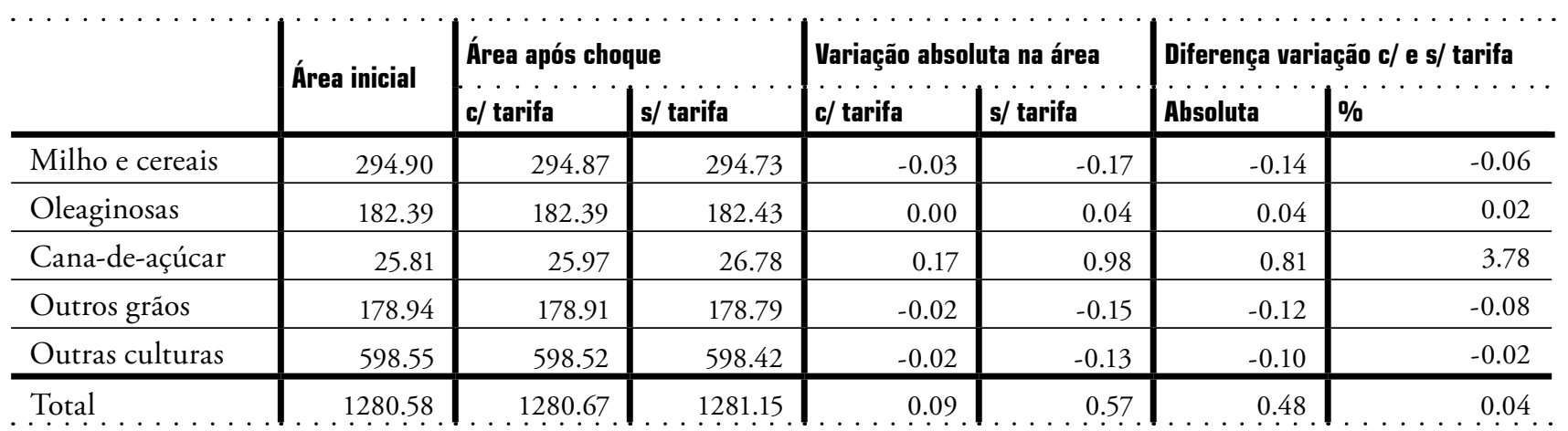

Fonte: Resultados do estudo 
nos pronunciados, já que cada novo hectare de pastagem ou floresta convertido para culturas é mais produtivo do que no conjunto de simulaçóes anterior.

Pode-se concluir dos resultados apresentados que a liberalização do comércio bilateral de etanol entre Brasil e Estados Unidos seria responsável pelo aumento da área de culturas agrícolas no mundo, representada principalmente pela cana-de-açúcar cultivada em território brasileiro e pelas sementes oleaginosas, no resto do mundo. Ainda, áreas de pastagens e de florestas seriam convertidas para dar espaço a maiores áreas de culturas. Contudo, o efeito de redução de florestas seria pouco pronunciado e menos expressivo que a conversão de pastagens, o que sugere mais intensificação das atividades agropecuárias do que expansão da fronteira agrícola. Outro aspecto importante desses resultados é que o ajuste do parâmetro que representa a produtividade de novas áreas agrícolas no modelo GTAP, proposto por Tyner et al. (2010), influencia fortemente os resultados na direção de menores conversões de áreas naturais. Tal ajuste pode ser considerado como uma pressuposição mais adequada no modelo, por considerar resultados científicos regionalizados de um modelo de ecossistemas terrestres para estimar a produtividade de novas áreas, ao invés de assumir que ocorre queda de $50 \%$ na produtividade da nova área em relação a áreas tradicionais de culturas no mundo como um todo, como assumido originalmente no modelo GTAP. ${ }^{7}$

\section{3_Comparação das emissões}

Os biocombustíveis ganharam grande atenção nos últimos anos como uma tecnologia capaz de contribuir para a redução na emissão de gases de efeito estufa. Contudo, mais recentemente essa contribuição tem sido contestada por críticos que apontam a possibilidade de que a expansão dos biocombustíveis aumente as taxas de desmatamento e a consequente emissão de grandes quantidades de $\mathrm{CO}_{2}$. Dessa forma, questiona-se se a quantidade de
${ }_{7} \mathrm{E}$ importante ressaltar que outros parâmetros e hipóteses do modelo GTAP também podem ter forte influência sobre os resultados encontrados. Um exemplo é a hipótese de retornos constantes à escala em todos os setores, implícita no modelo. Se considerarmos que muitas indústrias estão sujeitas a retornos crescentes de escala, o ganho de escala na indústria brasileira de etanol deveria gerar menor necessidade de aumento na produção de cana-de-açúcar para atender ao aumento nas exportaçóes desse produto, $\mathrm{o}$ que, por sua vez, reduziria os impactos negativos de mudanças no uso da terra. Contudo, a ausência de informações sobre a capacidade de aproveitamento de economias de escala existente na indústria brasileira de etanol limita a flexibilização da hipótese de retornos constantes no modelo. 
gás carbônico poupada pelo uso do etanol em substituição aos combustíveis fósseis compensaria as emissóes provocadas pelas mudanças no uso da terra.

De forma a contribuir para essa questâo, considerou-se a metodologia de cálculo de emissóes provenientes de mudanças no uso da terra pela expansão do etanol desenvolvida pelo California Air Resource Board (CARB, 2009), que inclui o uso do modelo GTAP, de forma a obter um coeficiente de intensidade de emissão de diferentes tipos de combustíveis, medido em termos de gramas $(\mathrm{g})$ de $\mathrm{CO}_{2}$ liberados por megajoule (MJ) de energia produzida. Aplicou-se o cálculo desse coeficiente aos resultados obtidos na presente pesquisa, considerando a emissão proveniente de mudanças no uso da terra estimada pelo modelo GTAP e a quantidade de energia que seria obtida pelos volumes de etanol simulado nos choques. Os resultados de emissóes e do coeficiente de intensidade de emissóes são apresentados na Tabela 9.

Percebe-se que a produção maior de etanol quando da remoção da tarifa norte-americana aumenta substancialmente a emissão de $\mathrm{CO}_{2}$ proveniente de mudanças no uso da terra, independentemente da escolha dos parâmetros. Contudo, o grande aumento em emissão, oriundo principalmente da redução na área de florestas, não se reflete em mudanças significativas no que concerne ao coeficiente de emissão por unidade de energia, uma vez que a quantidade de energia produzida a partir do etanol é bem maior nos cenários em que as tarifas são retiradas. Isso indica que a remoção da política protecionista americana não deve tornar o biocombustível brasileiro menos atrativo do ponto de vista de baixa emissão por unidade de energia, por conta de efeitos indiretos que a política possa causar sobre o desmatamento no país. Vale notar que as emissóes e os coeficientes de emissão são bem menores quando os parâmetros estimados por Tyner $e t a l$. (2010) são considerados no modelo.

Esse resultado é uma evidência importante da necessidade de se considerar parâmetros apropriados, estimados com rigor científico, nas análises de impactos de mudanças no uso da terra sobre a emissão de gases de efeito estufa. $\mathrm{O}$ uso do parâmetro original do GTAP, que supóe produtividade agrícola 50\% menor em áreas convertidas de florestas e pastagens para culturas, leva a emissóes e coeficientes que são mais do que o dobro dos estimados sob o uso de parâmetros mais apropriados.

É importante considerar ainda que o coeficiente calculado revela a emissão de $\mathrm{CO}_{2}$ por unidade de energia de biocombustível produzida, associada ao aumento da produção de biocombustível nos cenários com e sem tarifa de importação desse. 
Tabela 9_Emissão mundial de $\mathrm{CO}_{2}$ proveniente de mudanças no uso da terra (milhões de ton.) e coeficiente de emissão (gCo $/$ /MJ)

\begin{tabular}{|c|c|c|c|c|}
\hline Cenário & $\begin{array}{l}\text { Parâmetros do GTAP } \\
\text { Emissão } \\
\left(10^{6} \text { ton } \mathrm{CO}_{2}\right)\end{array}$ & $\begin{array}{l}\text { Coeficiente } \\
\text { (g Co } / \text { /MJ) }\end{array}$ & $\begin{array}{l}\text { Parâmetros de Tyner et al } \\
\text { Emissão } \\
\left(10^{6} \text { ton } \mathrm{CO}_{2}\right)\end{array}$ & Coeficiente \\
\hline Com tarifa & 31.87 & 45.55 & 14.23 & 20.34 \\
\hline Sem tarifa & 204.27 & 51.52 & 89.91 & 22.68 \\
\hline Diferença & 172.40 & 5.97 & 75.68 & 2.34 \\
\hline
\end{tabular}

Fonte: Resultados do estudo.

Assim, ele demonstra de forma clara quanto o biocombustível deixou de economizar em emissão por conta de mudanças indiretas no uso da terra. Como referência, o trabalho do CARB (2009) estimou que a gasolina emite $96 \mathrm{~g} \mathrm{CO}_{2} / \mathrm{MJ}$ por unidade de energia. Comparando-se esse valor com o encontrado para o etanol, mostra-se a vantagem que o biocombustível apresenta sobre o uso da gasolina. Quanto mais próximo for o coeficiente do biocombustível do coeficiente da gasolina, menos interessante esse se torna. Vale ressaltar que a emissão indireta do uso da terra deve ser adicionada à emissão direta proveniente do ciclo de vida do biocombustível. O CARB considera, para o etanol de cana-de-açúcar, emissão direta entre $12 \mathrm{~g} \mathrm{CO}_{2} / \mathrm{MJ}$ e $27 \mathrm{~g} \mathrm{CO}_{2} / \mathrm{MJ}$, dependendo do processo produtivo (mecanização na colheita e cogeração de eletricidade reduzem a emissão direta). A emissão indireta calculada por aquela instituição é o de $46 \mathrm{~g} \mathrm{CO}_{2} / \mathrm{MJ}$, o que é equivalente ao resultado do presente estudo para o caso da expansão do etanol brasileiro na presença da tarifa, com o parâmetro original do GTAP.

A Tabela 10 apresenta os intervalos de coeficientes totais mínimos e máximo de emissão por unidade de energia, obtidos a partir da soma dos resultados de emissáo do uso da terra obtidas no presente estudo e da emissão direta calculada pelo CARB. Com base nesta tabela, no pior cenário (parâmetros do GTAP, sem tarifa, emissão direta máxima), o etanol brasileiro chegaria a um coeficiente de $79 \mathrm{~g} \mathrm{CO}_{2} / \mathrm{MJ}$, o que representa 17 unidades a menos que a gasolina, ou 18\% de redução na emissão. Contudo, se forem utilizados os coeficientes de uso da terra mais apropriados, de acordo com os parâmetros de Tyner et al. (2010) e de emissóes diretas menores, o coeficiente 
Tabela 10_Coeficientes de emissão por unidade de energia $\left(g \mathrm{CO}_{2} / \mathrm{MJ}\right)$ parciais e totais para o etanol brasileiro

\begin{tabular}{|c|c|c|c|c|c|c|}
\hline & Cenário & Uso da terra & $\begin{array}{l}\text { Emissão direta } \\
\text { Mínima }\end{array}$ & Máxima & $\begin{array}{l}\text { Total } \\
\text { Mínimo }\end{array}$ & Máximo \\
\hline \multirow{2}{*}{ Parâmetros do GTAP } & Com tarifa & 46 & 12 & 27 & 58 & 73 \\
\hline & Sem tarifa & 52 & 12 & 27 & 64 & 79 \\
\hline \multirow{2}{*}{$\begin{array}{l}\text { Parâmetros de Tyner } \text { et al. } \\
\ldots \ldots \ldots \ldots \ldots \ldots\end{array}$} & Com tarifa & 20 & 12 & 27 & 32 & 47 \\
\hline & Sem tarifa & 23. & 12. & 27. & 35. & 50 \\
\hline
\end{tabular}

Fonte: resultados do estudo.

reduz-se para o intervalo de $32 \mathrm{~g} \mathrm{CO}_{2} / \mathrm{MJ}$ a $35 \mathrm{~g} \mathrm{CO}_{2} / \mathrm{MJ}$, o que representa cerca de 64\% a 66\% menos emissão que a gasolina. Ainda, a remoção da tarifa norte-americana aumentaria o coeficiente de emissão em apenas 3 a 4 gramas.

Considerando-se o grande aumento na comercialização de etanol (acréscimo de 1,26 bilhão de galóes comercializados com o fim da tarifa) perante a mudança relativamente pequena na emissão $(2,34$ $\mathrm{g} \mathrm{CO}_{2} / \mathrm{MJ}$ a mais emitidos no cenário dos parâmetros de Tyner et al.), tem-se que o uso do biocombustível continua vantajoso e capaz de reduzir substancialmente a emissão da gasolina. Isso indica que o aumento nas exportaçóes não é acompanhado de forma linear por aumento na emissáo, o que permite concluir que maiores quantidades de etanol brasileiro no mercado norte-americano contribuirão para a redução da emissão de gases de efeito estufa no setor de transporte.

\section{4_Impactos sobre os preços de alimentos}

Parte importante da discussão sobre a sustentabilidade dos biocombustíveis diz respeito a possíveis aumentos em preços de alimentos quando da expansão da produção de biomassa sobre áreas antes utilizadas para produzir culturas destinadas à alimentação, o que pode agravar os problemas de pobreza e desnutrição em países em desenvolvimento. O modelo GTAP fornece resultados sobre mudanças percentuais em índices de preços dos bens e serviços representados no modelo diante dos choques simulados. A Tabela 11, a seguir, apresenta as mudanças percentuais nos preços ao consumidor para as diferentes commodities agrícolas e alimentos nas regióes do modelo compostas de países em desenvolvimento, considerando os parâmetros do GTAP sobre produtividade de novas áreas.

Os impactos sobre os preços dos produtos agrícolas proporcionados pelos 
cenários de aumento nas exportaçóes brasileiras de etanol para os EUA são bastante modestos, sendo inferiores a $0,4 \% \mathrm{em}$ ambos os cenários e em todas as regióes de países em desenvolvimento, com exceção do Brasil. No Brasil, os maiores impactos em preços ao consumidor final são observados no cenário de remoção da tarifa de importação norte-americana e para os produtos cana-de-açúcar, como esperado, silvicultura, milho e grãos, outros produtos agrícolas e sementes oleaginosas. Apenas a cultura de cana-de-açúcar apresenta aumento pronunciado em preço, de cerca de 7\%, enquanto as demais culturas sofrem aumentos inferiores a $1,5 \%$. Os produtos da silvicultura sofrem aumentos de quase $3 \%$ em preços. Esses aumentos em preços refletem a competição direta da cana-de-açúcar para o etanol com as áreas de produção de outras culturas e de madeira de reflorestamento.

Vale notar, contudo, que a participação de produtos agrícolas e florestais não processados na cesta de consumo das famílias é geralmente bastante reduzida, uma vez que o consumo de alimentos industrializados e produtos processados tende a ser bem mais importante nos gastos das famílias. Produtos animais processados e outros alimentos sofrem aumentos de preços inferiores a $0,5 \%$, o que sugere impacto pouco expressivo sobre o consu- mo das famílias. Dessa forma, a remoção das tarifas de importação ao etanol por parte dos EUA não parece afetar os preços de alimentos no Brasil e no mundo a ponto de agravar problemas nutricionais e aumentar o número de famílias abaixo da linha de pobreza.

Alguns aspectos importantes sobre esses resultados merecem ser comentados. Primeiro, deve-se considerar a limitação do modelo GTAP em agregar diversos produtos em poucas categorias, o que reduz os impactos em preços de um ou outro produto particular, náo permitindo captar, por exemplo, o considerável aumento nos preços da commodity milho nos anos 2007 e 2008, comumente associado à forte expansão do etanol de milho nos EUA, entre outros aspectos da conjuntura mundial naqueles anos. Ainda, o modelo GTAP considera o equilíbrio de mercado que seria observado após o choque simulado ser completamente absorvido na economia, o que foge de um resultado de curto prazo de desequilíbrio entre oferta e demanda e baixos estoques mundiais.

Por fim, o modelo não considera famílias de diferentes classes de renda, e isso limita a capacidade de analisar questóes relacionadas à pobreza e à desigualdade de renda. Considerando que o efeito final de equilíbrio geral sobre as famílias envolve tanto as mudanças na renda a partir de al- 
Tabela 11_Mudanças percentuais em preços ao consumidor nas regiões compostas de países em desenvolvimento

\begin{tabular}{|c|c|c|c|c|c|c|c|c|c|}
\hline & Brasil & China & Índia & $\begin{array}{l}\text { América } \\
\text { Latina (export } \\
\text { de energia) }\end{array}$ & $\begin{array}{l}\text { Resto da } \\
\text { América Latina } \\
\text { e Caribe }\end{array}$ & $\begin{array}{l}\text { Oriente } \\
\text { Médio e Norte } \\
\text { da África }\end{array}$ & $\begin{array}{l}\text { África } \\
\text { Subsaariana }\end{array}$ & $\begin{array}{l}\text { Resto da } \\
\text { África }\end{array}$ & $\begin{array}{l}\text { Sul da Ásia } \\
\text { (export. de } \\
\text { energia) }\end{array}$ \\
\hline & \multicolumn{9}{|c|}{ Cenário com tarifa } \\
\hline Milho e grãos & 0,21 & 0,01 & 0,00 & 0,02 & 0,02 & 0,01 & 0,00 & 0,01 & 0,01 \\
\hline Outros grãos & 0,16 & 0,01 & 0,01 & 0,02 & 0,02 & 0,00 & 0,01 & 0,01 & 0,01 \\
\hline Sementes oleaginosas & 0,19 & 0,03 & 0,01 & 0,03 & 0,05 & 0,01 & 0,01 & 0,02 & 0,02 \\
\hline Cana-de-açúcar & 1,08 & 0,00 & 0,01 & 0,01 & 0,01 & 0,00 & 0,00 & 0,01 & 0,01 \\
\hline Pecuária & 0,12 & 0,00 & 0,00 & 0,01 & 0,01 & 0,00 & 0,00 & 0,00 & 0,00 \\
\hline Silvicultura & 0,42 & 0,01 & 0,01 & 0,02 & 0,02 & 0,01 & 0,01 & 0,02 & 0,01 \\
\hline Outros alimentos & 0,08 & 0,00 & 0,00 & 0,00 & 0,01 & 0,00 & 0,00 & 0,00 & 0,00 \\
\hline $\begin{array}{l}\text { Produtos animais } \\
\text { processados }\end{array}$ & 0,09 & 0,00 & 0,00 & 0,00 & 0,00 & 0,00 & 0,00 & 0,00 & 0,00 \\
\hline Outros produtos agrícolas & 0,21 & 0,00 & 0,00 & 0,01 & 0,01 & 0,00 & 0,00 & 0,01 & 0,01 \\
\hline Outros setores primários & 0,01 & 0,00 & 0,00 & 0,00 & 0,00 & $-0,01$ & 0,00 & 0,00 & 0,00 \\
\hline
\end{tabular}

Cenário sem tarifa

\begin{tabular}{|c|c|c|c|c|c|c|c|c|c|}
\hline Milho e grãos & 1,44 & 0,08 & 0,03 & 0,10 & 0,11 & 0,09 & 0,03 & 0,07 & 0,08 \\
\hline Outros grãos & 1,10 & 0,04 & 0,03 & 0,15 & 0,11 & 0,03 & 0,07 & 0,07 & 0,07 \\
\hline Sementes oleaginosas & 1,29 & 0,21 & 0,04 & 0,21 & 0,30 & 0,08 & 0,09 & 0,16 & 0,14 \\
\hline Cana-de-açúcar & 7,53 & 0,03 & 0,04 & 0,10 & 0,10 & 0,02 & 0,02 & 0,06 & 0,07 \\
\hline Pecuária & 0,73 & 0,01 & 0,02 & 0,04 & 0,04 & 0,00 & 0,00 & 0,01 & 0,01 \\
\hline Silvicultura & 2,95 & 0,06 & 0,05 & 0,13 & 0,15 & 0,10 & 0,09 & 0,16 & 0,07 \\
\hline Outros alimentos & 0,49 & 0,03 & 0,02 & 0,02 & 0,03 & 0,01 & 0,00 & 0,02 & 0,01 \\
\hline $\begin{array}{l}\text { Produtos animais } \\
\text { processados }\end{array}$ & 0,50 & 0,01 & 0,00 & 0,01 & 0,03 & 0,01 & 0,00 & 0,01 & 0,00 \\
\hline Outros produtos agrícolas & 1,43 & 0,03 & 0,03 & 0,06 & 0,07 & 0,03 & 0,02 & 0,06 & 0,05 \\
\hline Outros setores primários & 0,05 & $-0,01$ & $-0,01$ & $-0,01$ & $-0,01$ & $-0,03$ & $-0,02$ & $-0,01$ & $-0,01$ \\
\hline
\end{tabular}




\begin{tabular}{l|r|r|r}
$\ldots \ldots \ldots$ & $\begin{array}{l}\text { Resto da } \\
\text { Ásia (renda } \\
\text { elevada) }\end{array}$ & $\begin{array}{l}\text { Resto do } \\
\text { Sudeste e Sul } \\
\text { da Ásia }\end{array}$ & $\begin{array}{l}\text { Índice de } \\
\text { preço mundial }\end{array}$ \\
\hline & \multicolumn{3}{|c}{ Cenário com tarifa } \\
\hline Milho e grãos & 0,02 & 0,02 & 0,02 \\
\hline Outros grãos & 0,00 & 0,01 & 0,01 \\
\hline Sementes oleaginosas & 0,04 & 0,02 & 0,03 \\
\hline Cana-de-açúcar & 0,00 & 0,01 & 0,11 \\
\hline Pecuária & 0,01 & 0,00 & 0,01 \\
\hline Silvicultura & 0,01 & 0,01 & 0,02 \\
\hline Outros alimentos & 0,01 & 0,00 & 0,00 \\
\hline Produtos animais & & & 0,00 \\
\hline processados & 0,00 & 0,00 & 0,01 \\
\hline Outros produtos agrícolas & 0,00 & 0,01 & 0,00 \\
\hline Outros setores primários & 0,00 & 0,00 & \\
\hline
\end{tabular}

\section{Cenário sem tarifa}

\begin{tabular}{|c|c|c|c|}
\hline Milho e grãos & 0,16 & 0,12 & 0,11 \\
\hline Outros grãos & 0,03 & 0,05 & 0,06 \\
\hline Sementes oleaginosas & 0,24 & 0,12 & 0,23 \\
\hline Cana-de-açúcar & 0,01 & 0,06 & 0,80 \\
\hline Pecuária & 0,04 & 0,02 & 0,04 \\
\hline Silvicultura & 0,05 & 0,04 & 0,13 \\
\hline Outros alimentos & 0,07 & 0,02 & 0,03 \\
\hline $\begin{array}{l}\text { Produtos animais } \\
\text { processados }\end{array}$ & 0,02 & 0,01 & 0,02 \\
\hline Outros produtos agrícolas & 0,03 & 0,05 & 0,06 \\
\hline Outros setores primários & $-0,02$ & $-0,01$ & $-0,01$ \\
\hline
\end{tabular}

Fonte: Resultados do estudo. teração na remuneração dos fatores produtivos e no nível de emprego desses fatores quanto as mudanças em consumo proporcionadas por alteração nos preços dos bens e serviços ao consumidor final, a simples análise de mudança em preços aqui realizada busca apenas um indicativo simples e agregado sobre o possível aumento nos custos das famílias com produtos de origem agrícola, sem contudo representar uma análise precisa sobre o problema.

\section{5_Conclusões}

O presente estudo investiga como o comércio bilateral de etanol entre Brasil e Estados Unidos impacta as mudanças no uso da terra e na emissão de $\mathrm{CO}_{2}$. Considerando o comércio internacional desse biocombustível, verificou-se a potencialidade dos principais players desse mercado, notadamente Brasil e Estados Unidos. O lado americano, com o etanol de milho, sua vasta capacidade produtiva e o imenso mercado consumidor ainda a ser explorado, e o brasileiro, com a tradição na produção sucroalcooleira e consolidação do setor após o lançamento da tecnologia flex fuel. O maior entrave entre esses países é a existência de barreiras ao comércio bilateral que impedem a fluidez do etanol entre os dois mercados. Ainda, destaca-se o argumento de sustentabilidade duvidosa da produção de 
etanol, no que diz respeito à emissão relacionada às mudanças no uso da terra, como uma das críticas ao modelo de produção de combustíveis alternativos.

Para mensurar as consequências de um cenário de redução de barreiras comerciais entre o Brasil e os EUA sobre a sustentabilidade do etanol, foi utilizado um modelo de equilíbrio geral que permite estimar os efeitos que os choques de aumento na produção provenientes da liberalização do comércio teriam sobre mudanças no uso da terra e emissão de gases de efeito estufa. Os cenários permitiram concluir que a expansão da produção do biocombustível brasileiro proveniente de uma liberalização do comércio de etanol entre Brasil e Estados Unidos provocaria aumento em áreas desmatadas, seja por mudanças diretas, seja por mudanças indiretas no uso da terra, com consequente intensificação da emissão proveniente da remoçấo da cobertura vegetal.

Contudo, o aumento em emissão por mudanças no uso da terra mostra-se reduzido, entre $3 \mathrm{~g} \mathrm{CO}_{2} / \mathrm{MJ}$ e $6 \mathrm{~g} \mathrm{CO}_{2} / \mathrm{MJ}$, o que equivale a um incremento entre $6 \%$ e $10 \%$ de aumento na emissão total do etanol de cana-de-açúcar. Com isso, esses efeitos seriam compensados pela economia de emissão trazida pela maior substituição do uso de combustíveis fósseis nos veículos, uma vez que, pelo presente es- tudo, o aumento na produção de etanol de cana-de-açúcar pelo Brasil, diante de uma redução da tarifa norte-americana, está associado a emissão que pode ser até 66\% menor por unidade de energia em relação ao combustível de origem fóssil.

Assim, este estudo contribuiu com o cálculo quantitativo de ganhos para a sociedade de uma política de comércio mais favorável ao fluxo de energia renovável entre o Brasil e os EUA. A redução líquida na emissão de gases de efeito estufa e a redução do ritmo de crescimento do efeito estufa seriam os principais benefícios diretos. Além desses, enumeram-se todos aqueles relacionados ao aumento da produção nesse setor: aumento na geração de empregos, adição de maior valor à produção agrícola da cana-de-açúcar e incentivos aos setores relacionados figuram entre os mais importantes. Quanto às questóes sobre o desmatamento, devem-se buscar ganhos de produtividade, como os obtidos pela produção agrícola nos últimos anos, de forma a minimizar os impactos negativos da expansão da fronteira agrícola. Ainda, a definição e a aplicação crível da legislação sobre o uso da terra e ocupação do solo são essenciais para estabelecer os direitos de propriedade sobre as áreas produtivas e de preservação da vegetação natural, bem como das externalidades associadas. 
Por fim, é importante destacar que a definição de critérios de sustentabilidade e quantificação de emissão por unidade de energia que permita identificar o potencial de fontes alternativas em contribuir para a redução do problema climático é fundamental para definir rotas tecnológicas de menores impactos ambientais. Nesse sentido, os resultados aqui discutidos apontam o quanto as exportaçóes de etanol seriam capazes de contribuir para a redução de emissão de gases, considerando no cálculo os impactos negativos relacionados às mudanças no uso da terra.

Contudo, devem-se buscar alternativas de políticas que reduzam esses impactos negativos. Uma opção seria utilizar o coeficiente de emissão como forma de certificar ou mesmo penalizar o acréscimo em emissão, como previsto no RFS e na legislação do California Air Resource Board. Todavia, na ausência de certificaçóes e penalidades para todas as outras fontes emissoras de gases de efeito estufa, corre-se o risco de reduzir o incentivo à energia renovável baseada no uso da terra, uma vez que o processo de expansão da fronteira agrícola, quando gerado por mudança indireta, foge completamente ao controle do setor produtivo de biocombustíveis e, portanto, não tem como ser revertido pelo esforço desse setor.
Dessa forma, políticas públicas que reforcem o combate ao desmatamento, a definição dos direitos de propriedade e a aplicação da legislação ambiental e de uso da terra seriam opçóes mais efetivas de reduzir as emissóes indiretas de mudanças no uso da terra, sem reduzir o potencial de contribuição dos biocombustíveis em mitigar o problema da mudança climática. 


\section{Referências bibliográficas}

AHMED, S. A.; HERTEL, T.; LUBOWSKI, R. Calibration of a land cover supply function using transition probabilities. GTAP Research Memorandum, Center for Global Trade Analysis. Purdue University, West Lafayette, IN, 2008. Disponível em: <http://www.gtap.agecon. purdue.edu/resources/res_display. asp?RecordID $=2947>$. Acesso em: 12 abr. 2009.

\section{AMERICAN PETROLEUM} INSTITUTE, Statistics.

Disponível em: <http://www.api. org/statistics/>. Acesso em: 29 nov. 2010.

BABCOCK, B. A.; BARR, K.; CARRIQUIRY, M. Cost and benefits do taxpayers, consumers and producers from US ethanol policies. Disponível em: <http:// www.unica.com.br/multimedia/ documentos/>. Acesso em: 29 nov. 2010.
BECKMAN, J. F.; HERTEL, T. $\mathrm{W}$. Why previous estimates of the cost of climate mitigation are likely too low. GTAP Working Paper n. 54. Center for Global Trade Analysis, Purdue University, West Lafayette, IN, 2009. Disponível em: <https:// www.gtap.agecon.purdue. edu/resources/res_display. asp?RecordID $=3027>$. Acesso em: 19 out. 2010.

BIRUR, D. K.; HERTEL, T. W.; TYNER, W. E. Impact of biofuel production on world agricultural markets: A computable general equilibrium analysis. GTAP Working Paper n. 53. Center for Global Trade Analysis. Purdue University, West Lafayette, IN, 2008. Disponível em: <https:// www.gtap.agecon.purdue.edu/ resources/download/4034.pdf>. Acesso em: 17 out. 2010.

BRUCE, A. B.; CARRIQUIRY, M. An exploration of certain aspects of CARB's approach to modeling indirect land use from expanded biodiesel production. CARD Staff Report, Iowa, Feb. 2010. Disponível em: <http://www. cardiastate.edu>. Acesso em: 22 jun. 2010.
BURNIAUX, J. M.; TRUONG, T. GTAP-E: An energyenvironmental version of the GTAP model. GTAP Technical Paper n. 16. Center for Global Trade Analysis. Purdue University, West Lafayette, IN, USA, 2002. Disponível em: <https://www.gtap.agecon. purdue.edu/resources/res_display. asp? RecordID=923>. Acesso em: 12 mar. 2007.

\section{CALIFORNIA AIR RESOURCE} BOARD (CARB). Proposed regulation to implement the low carbon fuel standard, volume I, March 5, 2009. Disponível em: <http://www.arb.ca.gov/fuels/ lcfs/030409lcfs_isor_vol1.pdf>. Acesso em: 6 set. 2009.

\section{CONGRESS OF THE UNITED} STATES OF AMERICA. RFS2 -

Energy Independence and Security Act, 2007. Disponível em: <http:// frwebgate.access.gpo.gov/cgi-bin/ getdoc.cgi?dbname=110_cong _ bills\&docid=f:h6enr.txt.pdf $>$. Acesso em: 30 nov. 2010.

\section{DIMARANAN, B. V. (Ed.). Global} trade, assistance, and production: The GTAP 6 Data Base. Center for Global Trade Analysis, Purdue University, West Lafayette, IN, USA, 2006.
HERTEL, T. Global trade analysis: Modeling and applications. Cambridge: Cambridge University Press, 1997.

HERTEL, T. W.; GOLUB, A. A.; JONES, A., D.; O'HARE, M.; PLEVIN, R. J.; KAMMEN, D. M. Effects of US maize ethanol on global land use and greenhouse gas emissions: Estimating marketmediated responses. BioScience, vol. 60, n. 3, p. 223-231, 2010.

KEENEY, R.; HERTEL, T. W. The indirect land use impacts of United States biofuel policies: The importance of acreage, yield, and bilateral trade responses. American Journal of Agricultural Economics, v. 91, n. 4, p. 895-909, 2009.

LEE, H. L.; HERTEL, T. W.; ROSE, S.; AVETISYAN, M. An integrated land use data base for CGE analysis of climate policy options. In: HERTEL, T. W.; ROSE, S.; TOL, R. (Eds.). Economic Analysis of Land Use in Global Climate Change Policy. UK: Routledge Press. Chapter 4, 2009. 
LUBOWSKI, R. N.; PLANTINGA, A. J.; STAVINS, R. N. Landuse change and carbon sinks: Econometric estimation of the carbon sequestration supply function. Journal of Environmental Economics and Management, v. 51, p. 135-152, 2006. doi:10.1016/j. jeem.2005.08.001.

MCDOUGALL, R.; GOLUB, A.; GTAP-E. Release 6: A revised energy-environmental version of the GTAP model. GTAP Research Memorandum n. 15. Center for Global Trade Analysis. Purdue University, West Lafayette, IN, USA, 2009.

MONFREDA, C.; RAMANKUTTY, N.; FOLEY, J. A. Farming the Planet 2: The geographic distribution of crop areas and yields in the year 2000. Global Biogeochemical Cycles, 22, GB1022, 2008. doi:10.1029/2007GB002947.

NASSAR, A. Mudanças no uso da terra e a expansão da produção agrícola. 2009. Disponível em: <http://www.iconebrasil.org.br/pt $/$ ?act $\mathrm{A}=8$ \& areaID $=7 \&$ secaoID $=22$ \&artigoID $=1944>$. Acesso em: 28 nov. 2010 .

PIRES, A.; SCHECHTMAN R. Análise de preços de combustiveis e de politicas internacionais para a promoção de biocombustiveis. 2009. Disponível em <http:// www.unica.com.br/download. asp? $\mathrm{mmdCode}=2146 \mathrm{BF} 57-2049$ 4324-921A-BEC479970D36>. Acesso em: 29 nov. 2010.
RAMANKUTTY, N.; EVAN, A. T.; MONFREDA, C.; FOLEY, J. A. Farming the Planet 1: The geographic distribution of global agricultural lands in the year 2000. Global Biogeochemical Cycles, 22, GB1003, 2008. doi:10.1029/2007GB002952.

\section{RENEWABLE FUELS}

ASSOCIATION - RFA. Statistics

- Historic US fuel ethanol production. 2010a. Disponível em: <http://www.ethanolrfa.org/ pages/statistics\#A>. Acesso em: 29 nov. 2010.

\section{RENEWABLE FUELS}

ASSOCIATION - RFA. Importance of the VEETC to the U.S. economy and the ethanol industry. 2010b.

Disponível em: <http://www. ethanolrfa.org/pages/reports-andstudies>. Acesso em: 29 nov. 2010.

SCANDIFFIO, M. I. G. Análise prospectiva do álcool combustivel no Brasil-cenários 2004-2024. 2005. 182 f. Tese (Doutorado em Planejamento de Sistemas Energéticos) - Faculdade de Engenharia Mecânica, Universidade Estadual de Campinas, Campinas, 2005. SHOVEN, J. B.; WHALLEY, J. Applying general equilibrium. 3. ed. Cambridge: Cambridge University Press, 1998.

TAHERIPOUR, F.; BIRUR, D. K.; HERTEL, T. W.; TYNER, W. E. Introducing liquid biofuels into the GTAP data base. Research Memorandum 11. Center for Global Trade Analysis, Purdue University, West Lafayette, IN, USA, 2007.
TAHERIPOUR, F.; HERTEL, T. W.; TYNER, W. E.; BECKMAN, J. F.; BIRUR, D. K. Biofuels and their by-products: Global economic and environmental implications. 11th GTAP Conference, June 1214 2008. Disponível em: <https:// www.gtap.agecon.purdue.edu/ resources/download/3974.pdf>. Acesso em: 17 ago. 2010.

TYNER, W. E.; TAHERIPOUR, F.; ZHUANG, Q.; BIRUR, D.; BALDOS, U. Land use changes and consequent $\mathrm{CO}_{2}$ emissions due to US corn ethanol production: A comprehensive analysis. Department of Agricultural Economics, Purdue University, Final Report (Revised), July 2010.

UNIÁO DA INDÚSTRIA DA CANA-DE-AÇÚCAR - UNICA. Carta da UNICA enviada ao Conselho de Qualidade do Ar da Califórnia. 2009. Disponível em: <http://www.unica.com.br/ multimedia/publicacao/Default. asp?sqlPage $=2>$. Acesso em: 28 nov. 2010.

\section{U.S. ENERGY INFORMATION} ADMINISTRATION - EIA, Statistics, 2010. Disponível em: <http://www.eia.doe.gov/oil_ gas/petroleum/info_glance/ petroleum.html>. Acesso em: 28 nov. 2010.
Este estudo foi realizado com auxílio financeiro e bolsa fornecidos pelo CNPq.

E-mail de contato dos autores:

vnardy@gmail.com

angelo.gurgel@fgv.br

Artigo recebido em abril de 2011 e aprovado em fevereiro de 2012 
Parâmetros de razão de produtividade de novas áreas agrícolas

Anexo em relação a áreas tradicionais estimados por Tyner et al. (2010)

\begin{tabular}{|c|c|c|c|c|c|c|c|c|c|c|c|c|c|c|c|c|c|c|}
\hline ZAE* & 1 & 2 & 3 & 4 & 5 & 6 & 7 & 8 & g & 10 & 11 & 12 & 13 & 14 & 15 & 16 & 17 & 18 \\
\hline 1 & 0 & 0 & 0 & 0,91 & 0 & 0 & 0,93 & 0,95 & 0,95 & 0 & 0 & 0,61 & 0,61 & 0,61 & 1 & 1 & 1 & 1 \\
\hline 2 & 0 & 0 & 0 & 0,92 & 0 & 0 & 0,89 & 0,81 & 0,81 & 0 & 0 & 0,59 & 0,59 & 0,59 & 0 & 0 & 0 & 1 \\
\hline 3 & 0 & 0 & 0 & 0,93 & 0 & 0 & 0,86 & 0,9 & 0,9 & 0 & 0 & 0,89 & 0,89 & 0,89 & 1 & 1 & 1 & 0,74 \\
\hline 4 & 0 & 0 & 1 & 0,89 & 0 & 1 & 0,93 & 0,88 & 0,88 & 0 & 0 & 0,86 & 0,86 & 0,86 & 0,88 & 0,88 & 0,88 & 0,92 \\
\hline 5 & 0 & 0 & 0 & 0,93 & 0 & 0,9 & 0,98 & 0,88 & 0,88 & 0 & 0 & 1 & 1 & 1 & 0,9 & 0,9 & 0,9 & 0,96 \\
\hline 6 & 0 & 0 & 0 & 0,91 & 0 & 0,88 & 0,98 & 0,85 & 0,85 & 0 & 0 & 1 & 1 & 1 & 0,78 & 0,78 & 0,78 & 0,88 \\
\hline 7 & 0,73 & 0,89 & 0 & 0 & 0 & 0,8 & 0,9 & 0,59 & 0,59 & 0,98 & 0,98 & 0,46 & 0,46 & 0,46 & 0,43 & 0,43 & 0,43 & 0,65 \\
\hline 8 & 0,71 & 0,91 & 0,9 & 0 & 0 & 1 & 0,71 & 0,72 & 0,72 & 0,84 & 0,84 & 0,71 & 0,71 & 0,71 & 0,6 & 0,6 & 0,6 & 0,86 \\
\hline 9 & 1 & 0,85 & 1 & 0 & 1 & 0,98 & 0,88 & 0,91 & 0,91 & 0,82 & 0,82 & 0,77 & 0,77 & 0,77 & 1 & 1 & 1 & 0,93 \\
\hline 10 & 0,93 & 0,88 & 0,96 & 0,88 & 0,96 & 0,84 & 1 & 0,89 & 0,89 & 0,87 & 0,87 & 0,88 & 0,88 & 0,88 & 0,92 & 0,92 & 0,92 & 0,92 \\
\hline 11 & 0,96 & 1 & 0,83 & 1 & 0,94 & 0,95 & 0,9 & 0,87 & 0,87 & 0,89 & 0,89 & 0,77 & 0,77 & 0,77 & 0,79 & 0,79 & 0,79 & 0,96 \\
\hline 12 & 0,89 & 0 & 0,86 & 0,91 & 0,95 & 0,92 & 0,9 & 0,84 & 0,84 & 0,89 & 0,89 & 1 & 1 & 1 & 1 & 1 & 1 & 0,98 \\
\hline 13 & 0,92 & 0,55 & 1 & 0 & 0 & 1 & 1 & 1 & 1 & 0,63 & 0,63 & 0 & 0 & 0 & 1 & 1 & 1 & 0 \\
\hline 14 & 0,51 & 0,8 & 0,89 & 0 & 0 & 0,92 & 1 & 1 & 1 & 0,9 & 0,9 & 0 & 0 & 0 & 1 & 1 & 1 & 0 \\
\hline 15 & 0,71 & 0,83 & 0,9 & 0 & 1 & 1 & 1 & 0,64 & 0,64 & 0,87 & 0,87 & 0 & 0 & 0 & 1 & 1 & 1 & 1 \\
\hline 16 & 1 & 1 & 0,89 & 0 & 0 & 1 & 1 & 0,92 & 0,92 & 0,85 & 0,85 & 0 & 0 & 0 & 1 & 1 & 1 & 1 \\
\hline 17 & 0 & 0 & 0 & 0 & 0 & 1 & 0 & 1 & 1 & 0 & 0 & 0 & 0 & 0 & 0 & 0 & 0 & 1 \\
\hline 18 & 0 & 0 & 0 & 0 & 0 & 0 & 0 & 1. & 1 & 0 & 0 & 0 & 0 & 0 & 0 & 0 & 0 & 0 \\
\hline
\end{tabular}

* ZAE: Zonas agroecológicas de acordo com o modelo GTAP e com Lee et al. (2009).

Obs.: Valores iguais a zero indicam a inexistência da ZAE na regiâo. 